\title{
LA EVALUACIÓN DE LOS RECURSOS TERRITORIALES TURÍSTICOS DE CARÁCTER BÁSICO: EL CASO DE LAS PLAYAS DEL NORTE DE LA COMUNIDAD VALENCIANA
}

\author{
Diego López Olivares \\ Departamento de Historia, Geografía y Arte \\ Universidad Jaume I. Castellón
}

\section{RESUMEN}

Las playas de arena con calibres granulométricos bajos de las costas valencianas se caracterizan en general por ser recursos básicos ya que han provocado la atracción de la demanda, configurando, al desarrollar los elementos del «sistema turístico», el principal producto de la Comunidad Valenciana, el de «sol y playa».

Este sistema participa de dos subsistemas, el físico-natural y el social, actuando generalmente con falta de simbiosis, lo que repercute negativamente tanto en el medio como en la rentabilidad socio-económica. En este sentido intentamos aplicar una metodología de carácter analítico que nos permita evaluar y comparar la situación actual de esa relación entre ambos subsistemas en las playas del norte de la Comunidad Valenciana.

Palabras clave: Recursos básicos; análisis de playas; subsistemas natural y social; ponderación y evaluación.

\section{ABSTRACT}

Evaluation of basic regional tourist resources: a case study of the northern beaches of the region of Valencia. The sandy beaches along the Region of Valencia's coastline, with their low granulometric measurements, are well-known as a fundamental resource. They have generated great demand, by exploiting the elements of the «tourist system», given that they form part of the Region's main product, «sun, sea and sand».

This system is made up of two subsystems, which can be defined as nature and social activities and which do not normally go together. This has a negative impact on both the environment and socio-economic profitability. In this context, we attempt to apply an analytical methodology that allows us to evaluate and compare the present situation in relation to these subsystems in the northern beaches of the Region of Valencia.

Key words: Basic resources, analysis of beaches, natural and social subsystems, evaluation, Region of Valencia. 


\section{Introducción}

Los recursos territoriales, como componentes del «sistema turístico», constituyen la «materia prima» y forman junto con la oferta de alojamiento; la complementaria; las infraestructuras y servicios generales; la formación del personal; y otros como las tipologías edificatorias, el producto de una zona.

Pero ¿a qué denominamos recurso territorial turístico? En este sentido llamamos recurso a todo elemento material que tiene capacidad por sí mismo o en combinación con otros de atraer visitantes a un determinado espacio; y cuando esa visita responde a motivos estrictamente de turismo, ocio y recreación (López, 1998:35).

En el recurso adquiere valor propio el grado de funcionalidad que puede tener hasta el punto que ésta ha llevado a algunos autores (Gunn, 1988) a clasificar los recursos en básicos y complementarios.

Los recursos básicos son aquellos que tienen capacidad propia para atraer visitantes, y por lo tanto no poseen problemas de localización espacial. Entre ellos se encuentran desde un conjunto arquitectónico, a un parque natural o las mismas playas de arena fina. Por el contrario los complementarios la mayoría de las veces no poseen un atractivo claro por presentar jerarquías de valores bajos y su puesta en valor tiene que ir unida a la de otros atractivos turísticos.

Igualmente hay que diferenciar entre lo que son «recursos actuales» y «recursos turísticos potenciales». Aquéllos se caracterizan por ser en la actualidad el soporte de una actividad turística estructurada en la que se producen pernoctaciones; por el contrario lo potenciales, es evidente que aún se encuentran en proceso de ser incorporados a la dinámica turística y sobre todo no se presentan como productos al no haber desarrollado todos los elementos del «sistema turístico».

Así pues, las playas de arena fina o de calibres granulométricos bajos de las costas valencianas, se caracterizan en general por ser recursos básicos ya que han sido foco de atracción de la demanda, configurando, al desarrollar los elementos del «sistema turístico», el producto principal de la Comunidad Valenciana como es el turismo de «sol y playa». Ello viene refrendado por ubicarse el $72^{\prime} 6 \%$ de las plazas hoteleras de la Comunidad Valenciana en los espacios litorales, siendo este porcentaje aún mayor en el litoral de Castellón con el 77'9\%, a lo que hay que añadir las plazas extrahoteleras de campings, apartamentos turísticos, y sobre todo de segundas residencias, lo que representa para el litoral del norte valenciano el multiplicar por veinte el número de plazas con respecto a las hoteleras. A su vez este proceso de incremento de alojamientos ha representado importantes cambios en el territorio costero, sobre todo en el caso del uso del suelo (Navalón, 2001:384), funcionalidad y dinámicas socioeconómicas.

Sin embargo frente a la importancia socioeconómica que representa el turismo de «sol y playa», se encuentra la fragilidad del medio, ya que los componentes físico-naturales de las áreas de playa constituyen una unidad territorial homogénea y conforman, junto a los acantilados, los componentes más definitorios de la interfase tierra-mar.

El producto de «sol y playa» a menudo se ha venido desarrollando de forma espontánea, sobre todo a raíz del nacimiento allá por los años sesenta del siglo XX, del turismo de masas, generando en muchos casos actuaciones espaciales en su entorno contrarias al uso adecuado y vocacional de esos espacios, impidiendo procesos competitivos del producto.

Así, la importancia ambiental y socioeconómica que tienen las playas en el espacio litoral valenciano, nos ha llevado en este artículo a profundizar en el método de evaluación de las mismas, el cual hemos aplicado a la mitad norte del litoral castellonense el que reúne las principales playas las que a su vez han ido fijando el mayor número tanto de alojamien- 
tos turísticos y de segunda residencia como de visitantes en la costa septentrional del litoral valenciano.

\section{Objetivos}

El objetivo general es el análisis metodológico de carácter integrado de una serie de variables que procedentes de los subsistemas fisico-natural y social, nos permita evaluar la situación actual de las playas del norte de la Comunidad Valenciana, coincidiendo con los principales destinos turísticos castellonenses de «sol y playa», como son Vinaròs, Peníscola, Alcalà de Xivert (Alcossebre), Orpesa y Benicàssim.

Para ello partimos de la hipótesis de que la falta de simbiosis entre los dos subsistemas generan importantes tensiones entre ellos, repercutiendo tanto en el medio físico-natural como en la rentabilidad socieconómica del producto de «sol y playa». En este sentido es preciso compatibilizar la actividad turística con la conservación del medio, considerando a éste como factor intrínseco del recurso; es decir se genera la necesidad de la aplicación de un desarrollo turístico sostenible, identificando a éste en definición de Vera (2001:9), «con un proceso de cambio cualitativo producto de la voluntad política que, con la participación imprescindible de la población local, adopta el marco institucional y legal así como los instrumentos de planificación y gestión, a un desarrollo turístico basado en un equilibrio entre la preservación del patrimonio natural y cultural, la viabilidad económica del turismo y la equidad social del desarrollo».

Así, para la valoración del estado del producto de «sol y playa» de los diferentes destinos turísticos realizamos un estudio comparativo de las principales playas, cuyos objetivos específicos se fijan en:

- los impactos ambientales.

- calidad del agua de baño.

- capacidad de carga tanto física como ambiental y perceptual.

- superficie de arena de playa y sus índices granulométricos.

- densidades de edificación.

- estado de las infraestructuras y equipamientos.

Todos ellos son aspectos básicos para la implantación de una gestión de carácter integrado que nos facilite un desarrollo sostenible del litoral, por medio de la localización adecuada de los usos, teniendo en cuenta la intensidad de los aprovechamientos.

\section{Evaluación analítica e integrada de las playas como unidades básicas de atracción turística}

Las playas de arena fina de bajos calibres granulométricos, son un recurso turístico básico a nivel mundial y de ellas dependen muchos destinos turísticos. Así, por su trascendencia, en torno a estos recursos se han desarrollado diversas investigaciones y aplicaciones metodológicas con el objetivo de realizar evaluaciones sobre los referidos subsistemas tanto del medio natural como socioeconómico entre los que sobresalen fundamentalmente, por orden cronológico, las de la Organización de Estados Americanos (OEA) en 1978, Chavarri (1989), Williams et al. (1993), Leatherman (1997), o Morgan (1999).

Todos estos autores aplican en sus diferentes evaluaciones un análisis de diversos factores siendo común en todos ellos: el clima, la calidad del agua, la temperatura del agua, el material de la playa, la flora y la fauna, los accesos, y los vertidos de aguas residuales, ampliando cada uno de ellos los factores en función de las características de los espacios costeros analizados. 
En nuestro caso, el de los espacios mediterráneos, el producto de «sol y playa» se ha desarrollado con una escasa integración en el medio, especialmente en la primera línea de costa, originando tensiones territoriales derivadas del desarrollo escasamente armonioso con la vocación del espacio litoral, lo que contribuye a la devaluación cualitativa del destino tanto desde el punto de vista ambiental como socioeconómico. A tenor de ello su situación actual nos lleva a analizarlo y evaluarlo con un carácter integrado que refleje de manera objetiva la situación actual y que actúe como base para activar procesos capaces de garantizar la competitividad de estas áreas como productos turísticos, acorde con la sostenibilidad ambiental y socioeconómica.

El análisis, evaluación y ponderación de las áreas de playa como producto turístico viene precedido por la delimitación del espacio de la investigación. En aquella es preciso considerar dos áreas de análisis, la primera corresponde a una franja de $700 \mathrm{~m}$., ampliando en 200 m. la zona mínima de influencia de la ley de Costas de 1988, paralela a la línea de costa y medidos tierra adentro desde la isolínea $-2 \mathrm{~m}$., por ser la más concurrida y la que soporta la mayor parte de los desarrollos turísticos ligados al producto de «sol y playa». Respecto a la segunda, se aborda su análisis desde el enfoque espacial del destino atendiendo a la accesibilidad y a la demanda.

Una vez delimitada el área se procede a la elección de las variables, las que, como todo recurso territorial turístico, están distribuidas entre los factores internos y externos, que en este caso se corresponden con los subsistemas físico-natural y social.

Entre las variables pertenecientes a los factores internos podemos distinguir dos grandes conjuntos, por un lado aquel que reúne las variables intrínsecas del recurso territorial, distribuidas a su vez entre las que determinan las calidades de la superficie de playa, la calidad y temperatura del agua, las que configuran el paisaje, y el clima; y por otro, las que componen el grado de ordenación y planificación integrada del espacio delimitado de playa, es decir, aquéllas referentes a la infraestructura general y grado de planificación, y la oferta turística y de servicios (variables que para las áreas mediterráneas aún por ser condicionantes naturales del espacio litoral, dada la acelerada trayectoria de desarrollo producido a partir de la segunda mitad del siglo XX, han influido en las tendencias de la demanda).

Respecto a los factores externos del área de playa objeto de estudio, destacamos la accesibilidad y la demanda, que junto con los factores internos configuran el producto turístico en torno a la playa.

\subsection{Análisis y evaluación de las variables}

En general cada variable es valorada, dependiendo de su afección al entorno y a la calidad de la playa, de 0 a 3 cuando es positiva y de 0 a -3 si es negativa; sin embargo aunque algunas puedan compartir ambas jerarquías, la valoración vendrá determinada por el predominio de una de ellas (Bote, 1990; López, 1998a). Los resultados obtenidos son trasladados a una matriz que nos reflejará la puntuación global de cada bloque y su clasificación de 0 a 5 escalonada entre los valores mínimos y máximos teóricos.

No obstante esta aplicación genérica tiene una serie de especificidades por variables en cuanto a su evaluación. 


\subsubsection{Variables de los factores internos}

A) Variables intrínsecas

Respecto a las variables intrínsecas, como hemos adelantado, analizaremos en primer lugar aquéllas que se incluyen en la superficie de playa, entre ellas:

- La anchura de playa seca, la cual se considera el sector no cubierto por la marea alta. Los valores asignados van de 0 a -3 . El valor 0 se asigna al ancho de 41 a $80 \mathrm{~m}$., por ser la zona más frecuentada por los bañistas, y ofrecer, potencialmente densidades aceptables. El valor mínimo -3 corresponde por una parte a las anchuras inferiores a $10 \mathrm{~m}$, y por otra a las superiores a $120 \mathrm{~m}$., por exigir desplazamientos excesivos. Los valores intermedios -1 y -2 se aplican a los anchos de 10 a $40 \mathrm{~m}$. y 81 a $120 \mathrm{~m}$. respectivamente. Por lo que respecta al área de estudio, en el ritmo mensual de variación el mínimo lo obtiene marzo con una altura de $0.2 \mathrm{~cm}$. y el máximo lo alcanza el mes de octubre con $16.2 \mathrm{~cm}$. (Quereda y López, 1987).

- Granulometría de la arena. En esta variable los valores establecidos van de 0 a 3 . El mínimo, 0 , corresponde a tamaños gruesos $(2.00 \mathrm{~mm}$. - $0.60 \mathrm{~mm}$. $)$ o a la inexistencia de arena. El valor 1 se otorga a las arenas muy finas $(0.14-0.06 \mathrm{~mm}$.), si bien otorgan visualmente condiciones óptimas, resultan muy volátiles y se adhieren al cuerpo. Las granulometrías intermedias son las más favorables, asignando 3 a los calibres medianos (0.30 - $0.59 \mathrm{~mm}$.); y 2 para las arenas finas $(0.29-0.15 \mathrm{~mm}$.) y mezclas de granulometrías.

- La presencia de piedras constituye una variable negativa con lo cual los valores asignados oscilan de 0 a -3 . La inexistencia de piedras se valora con 0 . El valor 1 a la presencia de gravas $(2 \mathrm{~cm}$. a $2 \mathrm{~mm}$.), y a la combinación de gravas con cantos pequeños $(2$ - $6 \mathrm{~cm}$.) y medianos $(6-12 \mathrm{~cm}$.); de cantos $(2-24 \mathrm{~cm})$, y a la combinación de cantos con roquedos, se otorga -2 . El mínimo, -3 , a la presencia de bloques.

- La estabilidad de la playa es una variable que depende de la acción morfogenética de los factores físicos y de la acción antrópica; con lo cual el grado de actuación originará las situaciones ya mencionadas de regresión, equilibrio o progresión, teniendo en cuenta un período mínimo de 30 años. Así pues, la valoración será positiva o negativa, dependiendo del tipo de proceso. El valor 0 se asignará cuando la playa presente un perfil de equilibrio. Los valores positivos denotan la acción de los procesos de acumulación; corresponderá el valor 3 cuando la playa sea excepcionalmente progresiva; 2 si es muy progresiva; y 1 cuando es progresiva; el predominio de los procesos erosivos determinará la asignación de valores negativos; el mínimo, -3 , se otorga cuando la playa sea excepcionalmente regresiva; -2 si es muy regresiva; y -1 cuando es regresiva, es decir, la intensidad del proceso disminuye pero aún mantiene su presencia.

- La profundidad de la playa puede condicionar la afluencia y seguridad de los usuarios ya que viene determinada por la distancia existente entre el límite de la línea de bajamar y la isolínea $-2 \mathrm{~m}$. ausente de rocas y algas, siendo la zona que ofrece las condiciones óptimas para el disfrute del baño. Al tratarse de un elemento restrictivo que puede condicionar la afluencia y seguridad de los usuarios, se asignarán valores que van de 0 a -3 . El mínimo, -3, corresponde a los dos extremos, es decir, en distancias inferiores a $5 \mathrm{~m}$. y superiores a $50 \mathrm{~m}$.; esta última supone un desplazamiento excesivamente largo; -2 cuando se encuentra entre 5 y 15 m., y -1 de 15 a 30 m.; el valor 0 es el óptimo, y se asigna a la distancia que oscila entre 30 y $50 \mathrm{~m}$.

Otro bloque de variables intrínsecas está representado por la calidad del agua y su temperatura, ambas determinantes en la atracción de los usuarios. 
- La calidad del agua vendrá determinada por el grado de contaminación del agua dependerá, de los resultados obtenidos en los análisis de los parámetros microbiológicos y físico-químicos establecidos en el R.D. 734/1988 sobre la calidad de las aguas de baño. Los valores van de 0 a 3 . Se otorga 3 a las aguas que cumplen los valores guía e imperativos marcados en el Real Decreto antedicho; 2 se asigna a las aguas aptas para el baño que no sobrepasan los valores imperativos; y el 1 en las que se sobrepasan dichos valores pero aún son consideradas aptas para el baño. El valor 0 es otorgado a las aguas no aptas para el baño, o sin calificar.

- En cuanto a la temperatura del agua marina, sus valores constituyen uno de los elementos esenciales de la climatología turística. Así, al tratarse de una variable positiva, los valores oscilan entre 0 y 3 , de este modo se otorga el valor 3 cuando la temperatura del agua es superior a $25^{\circ} \mathrm{C}$ (cálida); 2 si oscila entre $21^{\circ} \mathrm{C}$ y $24^{\circ} \mathrm{C}$ (templada); el valor 1 para las temperaturas entre $21^{\circ} \mathrm{C}$ y $18^{\circ} \mathrm{C}$ (fresca); y finalmente el 0 si es inferior a $17^{\circ} \mathrm{C}$ (fría). Para nuestra área de estudio se han escogido los valores de los seis meses centrales del año dado que es cuando se concentra la mayor parte de la demanda turística.

Otro conjunto dentro de las variables intrínsecas lo componen el paisaje de la playa, cada vez más apreciado por los visitantes; entre aquellas se encuentran:

- la tonalidad o color de la arena, influye cada vez más en el atractivo de la playa, los valores asignados oscilan entre 0 y 3 , siendo más altos éstos cuanto más claros son los tramos. Así, el color gris tiene una aplicación de 1, el pardo de 2, y el beige o de tonalidades claras el máximo 3.

- la forma de la playa es uno de los principales condicionantes del paisaje costero aumentando el atractivo, cuanto más enmarcadas se hallan las visuales desde un punto central (Crhistolofoletti y Pires, 1980); por el contrario las línea rectilíneas de las playas hacen disminuir su atractivo. Por lo tanto partiendo de estos conceptos la valoración más positiva 3 se asigna a las playas con formas de bahía cerrada o arco cerrado, bajando su valoración a 2 las formas de arco semi-abierto y 1 a las que tienen forma abierta, correspondiendo a las convexas y rectilíneas la calificación de 0 .

- el relieve es también una de las variables a tener en consideración ya que origina unas tipologías de paisaje y una determinada morfología litoral. Los valores oscilan entre 0 y 3 , y éstos se aplican según el objetivo que tengamos, en este caso es el de las playas, por lo tanto las dificultades del medio físico salen penalizadas. Con esta apreciación se otorga el valor 0 al acantilado alto (>10 m.), y las marismas; 1 al acantilado medio (2-9 m.); 2 al acantilado bajo $(<2 \mathrm{~m}$.) y combinación de terrenos llanos y restinga de cantos; y 3 a terrenos con pendiente suave, montañas o estribaciones bajas.

- la vegetación junto con la fauna constituyen los elementos bióticos del paisaje, por lo tanto procede a analizar la tipología de comunidades y su estado de conservación. La valoración es positiva, correspondiendo el valor 0 a la inexistencia de vegetación, pastos o cultivos abandonados; el valor 1 a la superficie utilizada como cultivo o repoblaciones forestales; 2 si es ocupada por especies autóctonas degradadas; y el valor tres se asigna a la presencia de especies autóctonas bien conservadas.

El bloque de paisaje de playa se completa con la disponibilidad de terreno. La disponibilidad de terreno puede significar una restricción, por excluirse de esta variable la zona de dominio público marítimo-terrestre y considerar sólo el suelo clasificado como urbano o urbanizable. Por esta razón los valores van de 0 a -3 . Se otorgan los mínimos, -3 y -2 , a la inexistencia o escasez de terreno; -1 cuando es suficiente; y 0 si hay terrenos en exceso que posibiliten la planificación adecuada del desarrollo turístico.

Finalmente dentro de las variables intrínsecas analizamos el clima. La aplicación práctica de los factores y elementos del clima mediante los índices climático-turísticos nos dan 
a conocer el mayor o menor grado de confort y bienestar ambiental de determinados lugares. En nuestro espacio litoral hemos aplicado uno propio, que permite especificar y plasmar los puntos con similar benignidad y confort climático. En este índice se han considerado unos elementos positivos para la atracción turística: la temperatura y las horas de sol; y otros negativos: la precipitación y el número de meses húmedos a lo largo del año, los cuales suponen un rechazo para el visitante (López, 1990).

Los valores van de $0 \mathrm{a}-3$. En la aplicación del índice climático-turístico referido, corresponde el valor 0 cuando el resultado es superior a 4 , marcado por unas temperaturas medias situadas alrededor de los $17^{\circ} \mathrm{C}$ y las lluvias no llegan a los $500 \mathrm{~mm}$.; -1 cuando el resultado oscila entre 3.5 - 3.99, las temperaturas son algo más suaves, no llegan a los $17^{\circ} \mathrm{C}$ y las precipitaciones algo más elevadas que en el anterior; el valor -2 aparece entre 3 y 3.49, representa la transición entre un clima suave costero a otro más continentalizado y frío. El mínimo, -3 , corresponde al resultado situado entre 1.5 y 2.99 , las temperaturas oscilan de los $13^{\circ} \mathrm{C}$ a los $14.7^{\circ} \mathrm{C}$ y las precipitaciones entre los 600 y $700 \mathrm{~mm}$. Lógicamente en nuestra área de estudio no cabe las valoraciones -2 y -3 dado que estamos junto al mar y principalmente puede venir matizado este valor por la altitud.

B) Variables de ordenación y planificación integrada

Estas variables las hemos reagrupado en dos bloques, uno perteneciente a las infraestructuras generales y grado de planificación, caso de las infraestructuras básicas, características de la urbanización; uso del suelo en origen y la densidad; y otro referente a la oferta turística y servicios con el equipamiento y recursos, los servicios y la señalización y servicio de información.

— Las infraestructuras básicas, son las que influyen en la percepción de la calidad por parte de la demanda. Es necesario contemplar las infraestructuras urbanas; las características de los accesos y los aparcamientos.

Respecto a las infraestructuras urbanas hemos considerado la existencia de red y fuentes de agua potable; el alumbrado público; red de saneamiento y la depuración de agua. Los valores van de 0 a 3 ; obteniendo 0 si el área carece de las cuatro infraestructuras; 1 cuando carece de una o de dos; el valor 2 si posee tres de las infraestructuras y se encuentra entre 100 y $700 \mathrm{~m}$. del límite de la playa; y 3 cuando dispone de las cuatro y se encuentra a menos de $100 \mathrm{~m}$. del límite referido.

La exigencia de seguridad en el acceso al recurso y de confort recreativo para la práctica de actividades al aire libre, determina el análisis del tipo de acceso a la playa, ya sea rodado, peatonal, o paseos marítimos tanto peatonales como mixtos. Los valores considerados van de 0 a 3 y dependiendo de las exigencias de la demanda. Se otorga el valor 3 cuando el acceso es por medio de paseos marítimos ya sean peatonales o mixtos; 2 cuando es solamente peatonal; el valor 1, al acceso mixto; y 0 cuando es rodado, es decir, que aunque se pueda ir a pie, éste no se halla regulado.

En cuanto a los aparcamientos, el hecho de que en el área de estudio el automóvil sea el medio de transporte más utilizado en los desplazamientos, condiciona que el análisis se lleve a cabo atendiendo a la densidad y la regulación de los mismos. En el caso de la densidad, se considera adecuada si existe más de una plaza por plaza de alojamiento.

El valor máximo, 3 , se aplica cuando están regulados y la densidad es adecuada ( $>1$ plaza/alojamiento); 2 si están regulados pero la densidad es insuficiente con lo cual deberán calificarse más zonas de aparcamiento; 1 si no existe regulación aunque la densidad sea adecuada; y el valor 0 si aparecen problemas tanto de regulación como de densidad, o bien no existen. 
Otra variable importante es la referente a las características de la urbanización. Las estructuras de desarrollo urbanístico en el área interna del producto vienen condicionadas por la realidad socioeconómica del destino y el modelo de desarrollo diseñado por los instrumentos de planeamiento. En este sentido la valoración será negativa, obteniendo el valor mínimo, -3 , cuando predomina el desarrollo urbanístico en altura, -2 cuando es intensivo pero en profundidad; -1 cuando es incipiente, es decir tiene escaso desarrollo espacial, pero suele ser deficitario en infraestructuras urbanas, lo cual hace descender la calidad de la edificación; y el valor mínimo, 0, lo obtienen las áreas en las que no existe edificación por ubicarse en zonas protegidas, o se desarrolla una ocupación urbanística de baja densidad.

- La asignación de valores respecto a los usos del suelo en origen viene marcada por la calidad ambiental y estética del área; por lo tanto los usos del suelo albergan categorías positivas y negativas, valorándose de $3 \mathrm{a}-3$. Respecto a las positivas se otorga el valor 3 a los usos forestales y/ o naturales; 2 para los agrícolas; 1 cuando el uso es destinado a servicios; y 0 a la construcción extensiva con baja densidad. En la valoración de las categorías negativas, se otorga el valor -3 a los usos industriales e infraestructuras; -2 a la construcción intensiva en altura y profundidad.; y -1 para las zonas húmedas y ganadería intensiva.

- Densidad o capacidad de carga perceptual. El interés por establecer las densidades óptimas para fijar la capacidad de carga de las zonas de baño ha sido tratada en diferentes estudios. Así, Pearce (1988), recoge varias propuestas, entre las que citaremos las siguientes: en la costa del Languedoc-Rousillon se recomienda $15 \mathrm{~m}^{2}$ por usuario para una playa con 600 usuarios de media por Ha.; en la costa balcánica, $5 \mathrm{~m}^{2} / \mathrm{usuario}$; el Park and Recreation Information System (California) fija la densidad en $7 \mathrm{~m}^{2} / \mathrm{usuario}$; en Grecia, Piperoglou, elabora un coeficiente de uso óptimo para períodos punta según el tipo de playa y el segmento de demanda, variando la densidad de $20 \mathrm{~m}^{2} / \mathrm{usuario}$ para la clase alta en pequeña bahía, a $10 \mathrm{~m}^{2} /$ usuario para la clase media en bahía grande, y $6.6 \mathrm{~m}^{2} / \mathrm{usuario} \mathrm{si}$ el segmento pertenece a la clase baja en una playa alargada; y el Servicio de Ordenación del Litoral (Francia), asigna $25 \mathrm{~m}^{2} /$ usuario para una playa con una anchura de $25 \mathrm{~m}$.

El grado de utilización o densidad determinará la capacidad de carga que tiene una playa, establecida por su dimensión en $\mathrm{m}^{2}$ y relacionada, en nuestra área, con el potencial de usuarios, para períodos punta y en función del número de alojamientos $\left(4 \mathrm{x} \mathrm{n}^{\mathrm{o}}\right.$ de alojamientos), localizados en el área de periplaya. Considerando las citadas propuestas y la idoneidad con nuestro espacio, la densidad óptima se ha establecido entre $7-10 \mathrm{~m}^{2} / \mathrm{usuario}$. Por lo tanto, se tratará de analizar si la playa se encuentra en el nivel de uso recreativo adecuado que pueda mantener, sin un grado inaceptable de deterioro del recurso, la experiencia recreativa (Countryside Commission, 1970, citado en Blàzquez, 1994); o es superado, con lo cual desciende la calidad física y perceptual de la recreación; o no lo alcanza, bien por las características intrínsecas o bien por el escaso valor que alcanzan el resto de variables consideradas.

La aplicación de los valores son restrictivos ya que dicha densidad (7-10 $\mathrm{m}^{2} /$ usuario) puede verse sobrepasada o no alcanzada, con lo cual irán de 0 a -3. Así, se asignará el valor 0 cuando se alcanza la densidad recomendada; y -3 si se sobrepasa en exceso, $<4.9 \mathrm{~m}^{2} /$ usuario; -2 cuando se sitúa entre 5 y $6.7 \mathrm{~m}^{2} / \mathrm{usuario}$; y el -1 cuando no se alcanza, es decir, es superior a $10.1 \mathrm{~m}^{2} /$ usuario.

— Los equipamientos y recursos los componen fundamentalmente:

- El alojamiento comercial y complementario: viene dado en su análisis por la relación entre la oferta de alojamiento comercial, integrada por el número de establecimientos y plazas en hoteles, hostales y campings; y en complemento a 
éstos, el correspondiente valor para los restaurantes y bares-cafeterías. Dado el mayor peso específico que representa el alojamiento en hoteles y hostales, se le asigna un valor doble sobre la restauración. Cabe señalar que este valor ha sido aplicado en la zona de estudio, obteniéndose como resultado 126 plazas de media para el alojamiento comercial y 68 para los restaurantes.

Al tratarse de una variable positiva, los valores van de 0 a 3; así se asigna el valor 3 cuando entre las medias valoradas del alojamiento comercial y complementario existe una diferencia inferior al $25 \%$ del total entre ambos; 2 si esta diferencia es mayor del $25 \%$ en favor del alojamiento comercial; 1 si por el contrario la referida diferencia se encuentra a favor del complementario; y el mínimo, 0 , cuando carece de oferta.

- La variable turístico-residencial: se presenta bajo dos modalidades, las viviendas secundarias y los apartamentos turísticos, lo cual origina un diferente grado de especialización del destino que viene determinado por estos últimos al encontrarse regulados, tal como se refleja en la descripción de la variable. De este modo el valor 0 , se otorga cuando existe menos del $9 \%$ de apartamentos turísticos respecto al total de la oferta residencial, o se localiza más de una unidad residencial por hectárea cuando el área interna está clasificada como suelo no urbanizable, ya que denota un desarrollo espontáneo y deficitario en servicios urbanos. Los valores intermedios vienen dados cuando el porcentaje se sitúa entre el 29-10\% para el caso del valor 1, y del 49 al 30\% en el valor 2 . Cuando el porcentaje sobrepasa el $50 \%$ a favor de los apartamentos turísticos, o existen menos de una unidad por hectárea en suelo no urbanizable se le otorga la valoración máxima.

- Los establecimientos comerciales considerados, como el comercio detallista, se valoran en función de las categorías señaladas y el período de actividad de los mismos. El valor 0 se asigna cuando el área cuenta con menos del 50\% de las categorías de establecimientos y éstos sólo se encuentran abiertos durante el período de temporada; 1 si existen representadas más del $50 \%$, pero se encuentran abiertos sólo en temporada; el valor 2 indica una oferta real ya que pese a no alcanzar el $50 \%$ de las categorías, se encuentran abiertos durante todo el año; por último el valor 3 determina una diversificación de la oferta, al hallarse representadas más del $50 \%$ de las categorías y están abiertos durante todo el año.

- En la valoración del equipamiento recreativo y deportivo se considera el que existe en la playa y en el área interna del recurso. Siendo la valoración positiva, el valor máximo 3 lo alcanzan las áreas donde la oferta se ubica en la playa y en el entorno; 2 si sólo se encuentra en la playa; 1 cuando se localiza en el entorno; y 0 si carece de oferta.

- En cuanto a los recursos turísticos complementarios los resultados de esta variable se obtendrán a partir de la valoración de las jerarquías de los recursos ubicados en el área interna del producto. De este modo el mínimo 0, se otorga si predomina el valor de la jerarquía 1, es decir, son recursos que no tienen un valor por sí mismos, si no que complementan a otros. Los valores intermedios 1 y 2, corresponden el valor de las jerarquías 2 y 3 , es decir, motivan corrientes turísticas locales, y regionales respectivamente. El máximo 3, se otorga si predomina el valor de la jerarquía 4 , atractivo a nivel nacional.

- La disposición de servicios incide directamente sobre la demanda que utiliza el recurso de playa. Así, se consideran una serie de servicios básicos, ubicados 
tanto en la playa como en el área interna, siendo el caso de duchas, lavapiés, papeleras dentro y fuera de la playa, salvamento, socorrismo, W.C. públicos, limpieza de la arena y transporte público. Los valores intermedios se dan cuando hay ausencia de alguno, así el valor 1 se aplica cuando no alcanza el 50\% de los servicios, y el valor 2 cuando lo supera sin alcanzar la totalidad. Evidentemente el valor 0 se da cuando no ofrece ningún servicio.

- Señalización y servicio de información. Considerando esta variable como positiva, el valor mínimo 0 se otorga si el recurso carece de señalización y de servicio de información. Cuando sólo se encuentra señalizado o dispone solamente de servicio de información en la temporada estival, alcanza el valor 1. En cambio el valor 2 se asigna cuando existe señalización y servicio de información, aunque éste sea de temporada. Por último el valor 3, viene dado cuando está señalizado y dispone de servicio de información permanente.

\subsubsection{Variables de los factores externos}

El análisis de los factores externos completa la evaluación del producto de playa por medio de dos variables de gran importancia tanto para el recurso como para el destino. Estas se corresponden con la accesibilidad interna al área desde los principales puntos emisores y al predominio y volumen de demanda que genera.

\section{A) La accesibilidad al área}

La accesibilidad a los puntos de destino desde los principales centros emisores tanto nacionales como internacionales (en nuestra área de estudio Madrid, Comunidad Valenciana, Cataluña, Aragón, Castilla-La Mancha, País Vasco, Francia y Alemania, como principales demandantes de nuestras playas castellonenses), ha sido considerada a través de los tres medios de transporte, asignándose valores positivos. Su valoración vendrá otorgada por la suma de los tres y dependiendo del grado de utilización. En la distribución de los destinos y del medio de transporte utilizado para nuestra área de estudio se han empleado los resultados obtenidos de la encuesta realizada en agosto de 2000 por el Gabinete de Estudios Turísticos de la Universitat Jaume I, a 201 turistas alojados en hoteles de cuatro y tres estrellas de los municipios de Peníscola, Alcalà de Xivert-Alcossebre, Orpesa y Benicàssim.

Así pues, en el transporte por carretera, se otorga el valor 3 al recorrido no superior a las 6 horas; el 0 cuando excede de 12; y los valores intermedios, 1 y 2, para los períodos entre las 10-12 horas y 7-9 horas respectivamente.

En cuanto al transporte por ferrocarril, se asigna el valor 3 a las estaciones en las que paran más del $75 \%$ de los trenes; 2 corresponde a las que acogen entre el 75 y $50 \%$ de las paradas; 1 del 50 al 10\%; y 0 cuando el porcentaje es inferior al 10\%, sin parada o sin estación.

En el transporte aéreo se asigna el valor 3 al trayecto inferior a 30 minutos; 2 entre 30 y 60; 1 para trayectos entre 60 y 120; y 0 cuando es superior a 120 minutos, al contrarrestar el ahorro de tiempo que supone el transporte en avión.

B) Origen de la demanda

A partir de los resultados obtenidos en la encuesta la valoración vendrá determinada por el predominio en cuanto al origen de los visitantes, cuyo mayor o menor valor se otorga 
en función de la distancia de origen y de la tipología de las pernoctaciones. En este sentido el valor 0 , se otorga cuando en la distribución porcentual predomina el origen comarcal; 1 si predomina el regional; 2 si es nacional; y el máximo 3, cuando el predominio corresponde a la demanda de origen internacional.

\subsection{La ponderación de las variables de las playas}

Una vez valoradas las variables, es necesario aplicar un factor de ponderación a cada una de ellas, dado el diferente peso específico que ostenta cada una en función de los valores intrínsecos de las variables y de las exigencias y tendencias de la demanda. El valor de ponderación tendrá mayor peso específico en los factores internos con respecto a los externos por considerar que son fundamentales para que se produzca la demanda.

De este modo se elaborará una matriz de valoración ponderada para los factores internos y externos, en la cual la ponderación considerada para cada variable (Cuadro 1), multiplicará los resultados obtenidos en las anteriores matrices del apartado anterior.

\section{Cuadro 1}

PONDERACIÓN DE LOS FACTORES Y VARIABLES DEL RECURSO DE PLAYA

\section{Factores internos}

A: Evaluación de las características intrínsecas

\begin{tabular}{|l|c|}
\hline VARIABLES & PONDERACIÓN \\
\hline Características intrínsecas & \\
\hline Anchura playa seca & $\mathbf{0 . 0 4}$ \\
\hline Granulometría de la arena & $\mathbf{0 . 1 0}$ \\
\hline Presencia de piedras & $\mathbf{0 . 0 4}$ \\
\hline Estabilidad de la playa & $\mathbf{0 . 0 4}$ \\
\hline Profundidad de la playa & $\mathbf{0 . 1 0}$ \\
\hline Calidad del agua & $\mathbf{0 . 1 0}$ \\
\hline Temperatura del agua & $\mathbf{0 . 1 0}$ \\
\hline Color de la arena & $\mathbf{0 . 0 4}$ \\
\hline Forma de la playa & $\mathbf{0 . 1 0}$ \\
\hline Relieve & $\mathbf{0 . 0 4}$ \\
\hline Vegetación & $\mathbf{0 . 0 4}$ \\
\hline Disponibilidad de terreno & $\mathbf{0 . 1 0}$ \\
\hline Clima & $\mathbf{0 . 1 6}$ \\
\hline TOTAL & $\mathbf{1 . 0 0}$ \\
\hline
\end{tabular}


B: Evaluación del grado de ordenación y planificación integrada del recurso

\begin{tabular}{|l|c|c|}
\hline VARIABLES & \multicolumn{2}{|c|}{ PONDERACIÓN } \\
\hline Infraestructura general y grado de planificación & $\mathbf{0 . 3 0}$ \\
\hline Infraestructuras básicas & 0.15 & \\
- Infraestructuras urbanas & 0.10 & \\
- Características de los accesos & 0.05 & \\
- Aparcamientos & & $\mathbf{0 . 1 0}$ \\
\hline Características de la urbanización & & $\mathbf{0 . 0 5}$ \\
\hline Usos del suelo en origen & & $\mathbf{0 . 0 5}$ \\
\hline Densidad & & \\
\hline Oferta turística y servicios & & $\mathbf{0 . 2 5}$ \\
\hline Equipamientos y recursos & 0.05 & \\
- Alojamiento comercial y complementario & 0.05 & \\
- Residencial turístico & 0.05 & \\
\hline - Establecimientos comerciales & 0.05 & \\
\hline Servicios & 0.05 & \\
\hline Señalización y servicio de información & & $\mathbf{0 . 1 5}$ \\
\hline TOTAL turísticos complementarios & & $\mathbf{0 . 1 0}$ \\
\hline
\end{tabular}

\section{Y. Factores externos}

A: Evaluación la accesibilidad al área

\begin{tabular}{|l|c|}
\hline VARIABLES & PONDERACIÓN \\
\hline Accesibilidad interna & \\
\hline Accesibilidad a los puntos de destino & 0.50 \\
\hline TOTAL & $\mathbf{0 . 5 0}$ \\
\hline
\end{tabular}

B. Evaluación del recurso en el mercado turístico según el predominio de demanda que genera

\begin{tabular}{|l|c|}
\hline VARIABLES & PONDERACIÓN \\
\hline Demanda & \\
\hline Origen de la demanda & 0.50 \\
\hline TOTAL & $\mathbf{0 . 5 0}$ \\
\hline
\end{tabular}




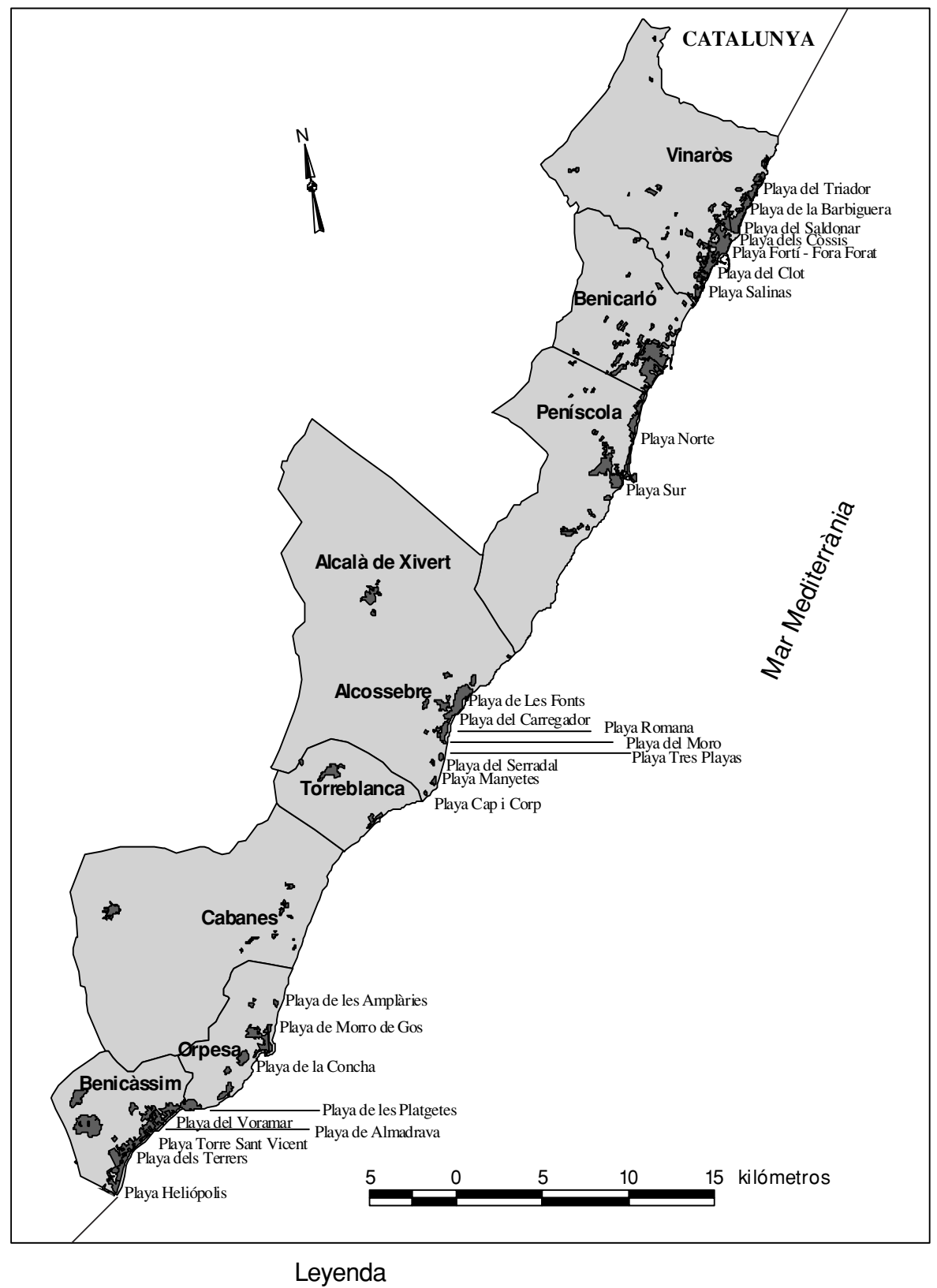

Municipios $\quad$ Areas urbanizadas

Elaboración propia.

FiguRa 1. Ubicación de las playas del área de estudio. 


\section{El caso de las playas del norte de la Comunidad Valenciana}

La zona de estudio se sitúa en la mitad norte de la costa castellonense a lo largo de 79’36 kms. distribuidos entre los términos municipales de Benicàssim, Orpesa, Cabanes, Torreblanca, Alcalà de Xivert, Peníscola, Benicarló y Vinaròs (Fig. 1). Estos participan de las diferentes estructuras litorales y morfogenéticas desde llanos, humedales, formaciones tombólicas, zonas motañosas, etc. las cuales influirán junto a otros elementos físiconaturales y las acciones antrópicas en el estado de las actuales playas costeras objeto de esta investigación.

\subsection{La evaluación de los factores y variables}

\subsubsection{Análisis de los factores y variables internas}

\section{A) Las características intrínsecas}

El resultado de analizar las siete primeras variables, es decir, aquellas que condicionan de manera más directa la calidad intrínseca de la playa, indica que gran parte de las playas del área de estudio alcanza la media e incluso la superan (Cuadro 2). En este sentido respecto a la anchura de la playa seca si bien es una variable restrictiva, alcanzan todas ellas los valores máximos, salvo la playa de Els Terrers en Benicàssim ya que en su tramo sur las olas baten directamente el acantilado y en el tramo norte las obras de regeneración han creado un área que supera los $80 \mathrm{~m}$. de anchura. No sucede lo mismo al analizar la granulometría de la arena, ya que en el extremo norte del área de estudio predominan las playas de cantos y en el resto son de calibres intermedios, es decir de arena fina; sin embargo en la recién regenerada playa Norte de Peníscola se ha optado por introducir arenas de calibre grueso procedentes del machaqueo de graveras continentales, propiedad de la empresa que ejecutó la obra, lo que ha hecho descender la valoración. Asimismo la combinación de arenas y gravas sucede en muchas de ellas, originada por la dinámica regresiva de la costa. En este sentido salvo la costa de Alcossebre y de Orpesa, donde predomina la estabilidad en la dinámica costera, en el resto son los procesos regresivos y las grandes infraestructuras los que inciden en la artificialización del recurso por parte de las administraciones públicas al objeto de conseguir estabilizar el frente costero. Del análisis de la estabilidad también se desprende que aquellas playas cuya evolución es progresiva se debe a las infraestructuras de defensa y regeneración, caso de la playa Sur de Peníscola, la de Les Fonts en Alcossebre o la de Les Platgetes en Orpesa. Asociada a la anterior variable se encuentra la profundidad, ya que cuando más acentuada es la dinámica regresiva la isolínea $-2 \mathrm{~m}$. se halla excesivamente próxima al sector de playa seca, como sucede en las playas de Vinaròs. Por el contrario en Peníscola, los valores mínimos vienen reflejados por el escaso gradiente batimétrico; en cambio los valores óptimos se concentran en la costa de Orpesa y en los tramos norte de Alcossebre y Benicàssim.

El área de baño se completa con el análisis de la calidad y la temperatura del agua, las cuales consiguen unas valoraciones por encima de la media a raíz de los buenos resultados de los análisis de los parámetros físico-químicos y microbiológicos del agua. En cambio los valores mínimos corresponden a las playas que o bien no se analizan, caso de la costa norte de Vinaròs, el tramo sur de Alcossebre y Les Platgetes de Bellver de Orpesa, o bien presentan una baja calidad del agua destacando en este sentido la playa Sur de Peníscola o la de Les Fonts de Alcossebre. En cuanto a la temperatura, al encontrarse entre los 21 y $24^{\circ} \mathrm{C}$, todas ellas obtienen la calificación de templada situándose muy cerca del óptimo. 


\section{Cuadro 2}

VALORACIÓN DE LAS PLAYAS DEL NORTE DE LA COMUNIDAD VALENCIANA SEGÚN LAS CARACTERÍSTICAS INTRÍNSECAS DE LOS FACTORES INTERNOS

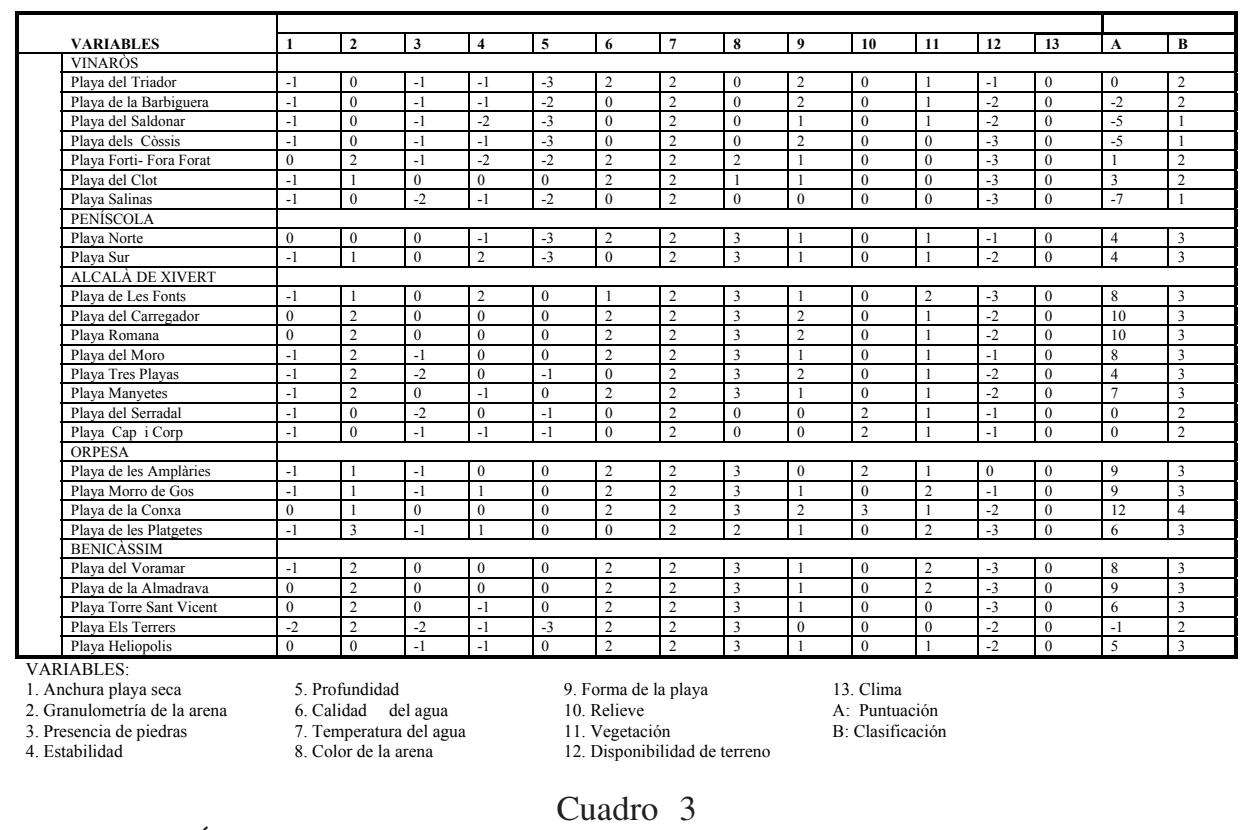

VALORACIÓN DE LAS PLAYAS DEL NORTE DE LA COMUNIDAD VALENCIANA SEGÚN EL GRADO DE PLANIFICACIÓN Y ORDENACIÓN INTEGRADA DE LOS FACTORES INTERNOS

\begin{tabular}{|c|c|c|c|c|c|c|c|c|c|c|c|c|c|c|c|c|}
\hline & \multirow{3}{*}{ VARIABLES } & \multicolumn{6}{|c|}{ Infraestructura general y grado de planificación } & \multicolumn{7}{|c|}{ Oferta turística y servicios } & \multirow{3}{*}{$\mathbf{A}$} & \multirow{3}{*}{ B } \\
\hline & & \multicolumn{3}{|c|}{1} & \multirow[t]{2}{*}{2} & \multirow[t]{2}{*}{3} & \multirow{2}{*}{4} & \multicolumn{5}{|c|}{5} & \multirow{2}{*}{6} & \multirow{2}{*}{7} & & \\
\hline & & 1.1 & 1.2 & 1.3 & & & & 5.1 & 5.2 & 5.3 & 5.4 & 5.5 & & & & \\
\hline & VINARÓS & & & & & & & & & & & & & & & \\
\hline & Playa del Triador & 1 & 2 & 0 & -1 & 2 & -1 & 1 & 0 & 0 & 0 & 0 & 2 & 1 & 7 & 2 \\
\hline & Playa de la Barbiguera & 2 & 2 & 0 & -2 & 2 & -2 & 1 & 0 & 0 & 0 & 0 & 1 & 1 & 5 & 2 \\
\hline & Playa del Saldonar & 2 & 1 & 0 & -2 & 2 & -2 & 1 & 0 & 0 & 0 & 0 & 1 & 1 & 4 & 1 \\
\hline & Playa dels Còssis & 2 & 1 & 2 & -2 & 2 & -3 & 2 & 0 & 0 & 0 & 0 & 1 & 1 & 6 & 2 \\
\hline & Playa Forti- Fora Forat & 2 & 3 & 2 & -3 & -2 & -3 & 1 & 0 & 3 & 3 & 3 & 3 & 3 & 15 & 3 \\
\hline & Playa del Clot & 2 & 1 & 0 & -2 & $\left.\begin{array}{|l|}-3 \\
\end{array}-x-2\right)$ & -3 & 1 & 0 & 0 & 2 & 1 & 2 & 1 & 2 & 1 \\
\hline & Playa Salinas & 2 & 0 & 0 & -2 & 3 & -2 & 1 & 0 & 0 & 0 & 0 & 1 & 1 & 4 & 1 \\
\hline & \begin{tabular}{|l|} 
PENISCOLA \\
\end{tabular} & & & & & & & & & & & & & & & \\
\hline & \begin{tabular}{|l|} 
Playa Norte \\
\end{tabular} & 3 & 3 & \begin{tabular}{|l|l}
2 \\
\end{tabular} & -3 & 2 & 0 & 3 & 11 & 1 & 3 & 3 & 3 & 3 & 24 & 4 \\
\hline & \begin{tabular}{|l} 
Playa Sur \\
\end{tabular} & 3 & 3 & 2 & -2 & $\begin{array}{ll}0 \\
\end{array}$ & 0 & 1 & 0 & 3 & 2 & 3 & 3 & 2 & 20 & 4 \\
\hline & \begin{tabular}{|l} 
ALCALA் DE XIVERT \\
\end{tabular} & & & & & & & & & & & & & & & \\
\hline & \begin{tabular}{|l|} 
Playa de Les Fonts \\
\end{tabular} & 2 & 3 & 2 & 0 & 2 & -3 & 1 & 0 & 1 & 3 & 0 & 2 & 2 & 15 & 3 \\
\hline & \begin{tabular}{|l|} 
Playa del Carregador \\
\end{tabular} & 2 & 1 & 0 & -2 & 2 & -2 & 1 & 0 & 3 & 2 & 1 & 3 & 3 & 14 & 3 \\
\hline & \begin{tabular}{|l|} 
Playa Romana \\
\end{tabular} & 1 & 0 & 0 & 0 & 2 & -2 & 1 & 0 & 0 & 2 & 0 & 3 & 2 & 9 & 2 \\
\hline & \begin{tabular}{|l|} 
Playa del Moro \\
\end{tabular} & 1 & 0 & 0 & 0 & 2 & -3 & 2 & 0 & 0 & 2 & 0 & 2 & 1 & 7 & 2 \\
\hline & \begin{tabular}{|l} 
Playa Tres Playas \\
\end{tabular} & 1 & 0 & 0 & -1 & 2 & -1 & 2 & 0 & 0 & 0 & 0 & 1 & 1 & 5 & 2 \\
\hline & \begin{tabular}{|l|} 
Playa Manyetes \\
\end{tabular} & 1 & 0 & 0 & -1 & 2 & -1 & 1 & 0 & 0 & 2 & 0 & 2 & 1 & 7 & 2 \\
\hline & Playa del Serradal & 1 & 0 & 0 & -1 & 2 & -1 & 1 & 0 & 0 & 0 & 0 & 1 & 1 & 4 & 1 \\
\hline & Playa Cap i Corp & 1 & 0 & 0 & -1 & 2 & -1 & 0 & 0 & 0 & 0 & 1 & 1 & 1 & 4 & 1 \\
\hline & ORPESA & & & & & & & & & & & & & & & \\
\hline & Playa de les Amplàries & 1 & 1 & 0 & -3 & 2 & -2 & 3 & 0 & 0 & 3 & 0 & 1 & 0 & 6 & 2 \\
\hline & Playa Morro de Gos & 3 & 3 & 3 & -2 & 2 & -3 & 1 & 0 & \begin{tabular}{|l|l}
0 \\
\end{tabular} & 3 & 1 & 3 & 22 & 15 & 3 \\
\hline & \begin{tabular}{|l} 
Playa de la Conxa \\
\end{tabular} & 3 & 3 & 2 & -3 & 2 & -3 & 1 & 0 & 1 & 2 & 1 & 3 & 3 & 15 & 3 \\
\hline & Playa de les Platgetes & 1 & 3 & 2 & -2 & 3 & 0 & 2 & 0 & 0 & 1 & 1 & 1 & 1 & 13 & 3 \\
\hline & \begin{tabular}{|l|} 
BENICÁSSIM \\
\end{tabular} & & & & & & & & & & & & & & & \\
\hline & \begin{tabular}{|l} 
Playa del Voramar \\
\end{tabular} & 3 & 3 & 2 & -2 & 0 & -1 & 2 & 0 & 0 & 3 & 1 & 2 & 1 & 14 & 3 \\
\hline & \begin{tabular}{|l|} 
Playa de la Almadrava \\
\end{tabular} & 3 & 3 & 2 & -3 & 2 & -2 & 1 & 0 & 1 & 2 & 1 & 3 & 1 & 14 & 3 \\
\hline & \begin{tabular}{|l} 
Playa Torre Sant Vicent \\
\end{tabular} & 3 & 3 & 1 & -3 & 2 & 0 & 1 & 0 & 0 & 2 & 1 & 2 & 22 & 14 & 3 \\
\hline & \begin{tabular}{|l} 
Playa Els Terrers \\
\end{tabular} & 2 & 11 & 2 & -3 & 2 & -3 & 3 & 0 & 1 & 3 & 0 & 3 & \begin{tabular}{|l|l}
1 \\
\end{tabular} & 12 & 3 \\
\hline & \begin{tabular}{|l|} 
Playa Heliopolis \\
\end{tabular} & 3 & 3 & 0 & -3 & 2 & 0 & 1 & 0 & 1 & 2 & 0 & 3 & 2 & 14 & 3 \\
\hline \multicolumn{17}{|c|}{ VARIABLES: } \\
\hline 1. & Infraestructuras básicas & \multicolumn{4}{|c|}{ 5. Equipamientos y recursos } & & & \multicolumn{9}{|c|}{ 6. Servicios } \\
\hline 1.1 & Infraestructuras urbanas & \multicolumn{6}{|c|}{ 5.1. Alojamiento comercial y complementario } & \multicolumn{9}{|c|}{ 7. Señalización y servicio de información } \\
\hline & Características de los accesos & \multicolumn{6}{|c|}{ 5.2. Residencial turístico } & \multicolumn{9}{|c|}{ A: Puntuación } \\
\hline 1.3 & Aparcamientos & & ablec & ntos $\mathrm{c}$ & ercia & & & & lasific & ión & & & & & & \\
\hline 2. & Características de la urbanización & & uipan & depc & ivo $\mathrm{y}$ & creat & & & & & & & & & & \\
\hline 3. & Usos del suelo en origen & & ursos & ticos & mple & entar & & & & & & & & & & \\
\hline 4. & Densidad & & & & & & & & & & & & & & & \\
\hline
\end{tabular}


La calidad de las playas viene a su vez condicionada por la calidad visual del paisaje costero, que aparece definida por una serie de variables donde se integra el color de la arena, la forma de la playa, los rasgos fisiográficos del relieve, la fragilidad y diversidad de la vegetación y la disponibilidad de terreno. En consecuencia, del análisis del color de la arena se desprende un claro predominio de las tonalidades claras, obteniendo así el valor óptimo, que sólo se ve reducido al valor mínimo por aquellas que como es obvio son de cantos o gravas, o en las que la arena es de tonalidades oscuras, como es el caso de la playa del Clot de Vinaròs o de Les Platgetes de Orpesa. Asimismo siendo positiva la valoración de la forma de la playa, la configuración de la costa predispone a que sean las formas abiertas las más representativas, ello origina a menudo formas artificiales, facilitadas por los espigones o diques portuarios, que hacen descender la valoración al modificar la morfología y el paisaje original. En esta línea descendente influye también las propias características físicas de la morfología litoral, por tratarse esencialmente de una costa llana; del total de playas analizadas, solamente obtienen el máximo la playa de la Concha de Orpesa, debido a la proximidad de las estribaciones montañosas con pendiente suave. De la misma manera el análisis de la vegetación litoral se sitúa en valores mínimos dada la tradicional presión ejercida sobre los ecosistemas sobre todo por la expansión urbanística. En cuanto a la disponibilidad de terreno, variable que indica la posibilidad que existe en la actualidad de planificar adecuadamente el desarrollo turístico, la excesiva clasificación de suelo urbano y urbanizable, origina un claro predominio de los valores mínimos que indican bien la inexistencia o escasez de terreno. Sin embargo en la costa sur de Alcossebre y en la playa de Les Amplàries de Orpesa, pese a estar comprometidas para el uso residencial, aún no se ha completado el proceso edificatorio, lo cual posibilita introducir nuevos parámetros que consigan crear un producto diferenciado, más acorde con la vocación del territorio y el paisaje litoral.

\section{B) El grado de planificación y ordenación integrada}

Como hemos significado conviene diferenciar dos bloques de variables, el primero de ellos integra aquéllas que referencian la infraestructura general y el grado de planificación actual, comprendiendo el análisis de las infraestructuras urbanas, las características de la urbanización, los usos del suelo en origen y la densidad que puede alcanzar en función de la dimensión y el volumen de demanda que acoge (Cuadro 3).

Respecto a las infraestructuras básicas que comprenden las infraestructuras urbanas, los accesos a la zona de baño y los aparcamientos, del análisis se desprende que las mejores valoraciones se corresponden con aquellas playas que se hallan más próximas a los cascos urbanos o en las que existe una mayor urbanización de la primera línea. No obstante en casi todas ellas son los aparcamientos el componente más deficitario, debido a que la alta densidad hace que sean insuficientes o a la inexistencia de su regulación.

Por otra parte los instrumentos de planeamiento marcan las características de la urbanización y en definitiva el modelo de desarrollo urbanístico. Del análisis de esta variable se constatan claras diferencias, destacando el desarrollo extensivo en el litoral de Vinaròs y el intensivo de Benicàssim, la playa Norte de Peníscola o la de la Concha de Orpesa; éstos contrastan con el desarrollo incipiente de la costa sur de Alcossebre, los cuales no favorecen la creación de escenarios urbanos atractivos e integrados en el paisaje.

Otra de las variables que denota el grado de planificación del recurso se traduce en los usos del suelo en origen, es decir antes de que se produjera la irrupción del turismo masivo. Al contrario que en la variable anterior, la mayoría de las playas ofrecen resultados positivos que superan la media a raíz del predominio de los usos agrícolas; los valores 
negativos sólo aparecen en las playas del Clot por la existencia de usos industriales y en la playa Fortí-Fora Forat por la intensidad de la construcción. En el sentido opuesto, es decir, con la máxima valoración, se encuentra la playa de Les Platgetes de Bellver de Orpesa.

Este bloque de variables se completa con la densidad, la cual determina el número de usuarios que puede acoger la playa en función, como ya se ha adelantado, de las dimensiones del sector de playa seca y del potencial de visitantes que puede albergar el área interna del recurso en función del proceso edificatorio. Después del análisis se constata que las playas de Peníscola y Benicàssim son las que presentan los mejores resultados, en cambio en Orpesa y Vinaròs, sus principales playas, caso de la Concha y Morro de Gos y la del Fortí-Fora Forat, sobrepasan en exceso la densidad óptima, al igual como sucede en las playa de Les Fonts y en la del Moro en Alcossebre.

Los resultados del análisis del segundo bloque de variables nos permitirán calibrar la situación actual de la oferta turística y los servicios con que cuenta el área interna del recurso así como su calidad, diversificación y el grado de estacionalidad que presentan. Así, se consideran dentro del equipamiento y recursos, el alojamiento comercial y complementario, el residencial turístico, los establecimientos comerciales, el equipamiento deportivo y recreativo, y los recursos turísticos complementarios; éstos se completan con los servicios, y la señalización y los puntos de información de que dispone.

Teniendo en cuenta los valores obtenidos se constata un déficit general de plazas en alojamiento comercial, tan sólo en la playa Norte de Peníscola, Les Amplàries en Orpesa y la playa de Els Terrers de Benicàssim, éste supera al complementario. Aún más acusado es el déficit de la oferta regulada de apartamentos turísticos, lo cual plasma el predominio de las segundas residencias, así como de una importante oferta no regulada. También se sitúa por debajo de la media la oferta de establecimientos comerciales, que viene marcada por la escasa diversificación y la alta estacionalidad de los destinos, ya que solamente las playas ubicadas en los cascos urbanos son las que alcanzan el óptimo, como sucede en Vinaròs, Peníscola y Alcossebre. Sin embargo mejores resultados ofrece la oferta de equipamiento recreativo y deportivo, dado el constante esfuerzo de las administraciones públicas. Por último, del análisis de los recursos turísticos complementarios cabe señalar un claro predominio de las jerarquías bajas, es decir, aquellos recursos que no tienen un valor por sí mismos, sino que complementan a otros, y de los que motivan corrientes turísticas locales; solamente las playas de Peníscola y la del Fortí-Fora Forat de Vinaròs alcanzan el máximo, por los acontecimientos programados que se desarrollan en el área interna.

Si bien todas las playas analizadas disponen de servicios, lo que refleja las inversiones que están realizando las administraciones públicas de acuerdo con las exigencias de la demanda, de los componentes considerados en el momento de analizar esta variable cabe destacar que los déficits que hacen descender la valoración se concentran en las papeleras ubicadas fuera de la playa y en los W.C. públicos.

Es evidente que entraña suma dificultad dotar a cada playa de un servicio permanente de información, sin embargo debemos destacar que todos los destinos analizados salvo Benicàssim, lo disponen en alguna de sus playas, lo mismo sucede con la señalización del recurso, a excepción de la playa de Les Amplàries de Orpesa. No obstante en cuanto al servicio de información en temporada estival si bien lo disponen las principales playas, en cambio amplios sectores carecen de él, como ocurre en el litoral norte de Vinaròs, el tramo central de Alcossebre, en las playas de Les Amplàries y Les Platgetes de Bellver de Orpesa, o en el sector norte de Benicàssim. 
Cuadro 4

VALORACIÓN DE LAS PLAYAS DEL NORTE DE LA COMUNIDAD VALENCIANA SEGÚN LA ACCESIBILIDAD. FACTORES EXTERNOS

\begin{tabular}{|c|c|c|c|}
\hline & $\begin{array}{c}\text { ACCESIBILIDAD } \\
\text { INTERNA }\end{array}$ & & $\begin{array}{c}\text { ACCESIBILIDAD } \\
\text { INTERNA }\end{array}$ \\
\hline & A los puntos de destino & & A los puntos de destino \\
\hline VINARÒS & & Playa Tres Playas & 1 \\
\hline Playa del Triador & 2 & Playa Manyetes & 1 \\
\hline Playa de la Barbiguera & 2 & Playa del Serradal & 1 \\
\hline Playa del Saldonar & 2 & Playa Cap i Corp & 1 \\
\hline Playa dels Còssis & 2 & ORPESA & \\
\hline Playa Forti - Fora Forat & 2 & Playa de les Amplàries & 2 \\
\hline Playa del Clot & 2 & Playa Morro de Gos & 2 \\
\hline Playa Salinas & 2 & Playa de la Conxa & 2 \\
\hline PENÍSCOLA & & Playa de les Platgetes & 2 \\
\hline Playa Norte & 2 & BENICÁSSIM & \\
\hline Playa Sur & 2 & Playa del Voramar & 2 \\
\hline ALCALȦ DE XIVERT & & Playa de la Almadrava & 2 \\
\hline Playa de Les Fonts & 1 & Playa Torre Sant Vicent & 2 \\
\hline Playa del Carregador & 1 & Playa Els Terrers & 2 \\
\hline Playa Romana & 1 & Playa Heliopolis & 2 \\
\hline Playa del Moro & 1 & & \\
\hline
\end{tabular}

Elaboración propia

\section{Cuadro 5}

VALORACIÓN DE LAS PLAYAS DEL NORTE DE LA COMUNIDAD VALENCIANA SEGÚN EL PREDOMINIO DE DEMANDA QUE GENERAN. FACTORES EXTERNOS

\begin{tabular}{|c|c|c|c|}
\hline & \multirow{2}{*}{$\begin{array}{c}\text { DEMANDA } \\
\text { Origen de la demanda } \\
\end{array}$} & & \multirow{2}{*}{$\begin{array}{c}\text { DEMANDA } \\
\text { Origen de la demanda }\end{array}$} \\
\hline & & & \\
\hline VINARÓS & & \begin{tabular}{|l|} 
Playa Tres Playas \\
\end{tabular} & 3 \\
\hline Playa del Triador & 2 & $\begin{array}{l}\text { Playa Manyetes } \\
\end{array}$ & 3 \\
\hline Playa de la Barbiguera & 2 & \begin{tabular}{|l|} 
Playa del Serradal \\
\end{tabular} & 3 \\
\hline Playa del Saldonar & 2 & \begin{tabular}{|l} 
Playa Cap i Corp \\
\end{tabular} & 3 \\
\hline Playa dels Còssis & 2 & ORPESA & \\
\hline Playa Forti - Fora Forat & 2 & Playa de les Amplàries & 2 \\
\hline Playa del Clot & 2 & \begin{tabular}{|l|} 
Playa Morro de Gos \\
\end{tabular} & 2 \\
\hline Playa Salinas & 2 & Playa de la Conxa & 2 \\
\hline PENÍSCOLA & & \begin{tabular}{|l|} 
Playa de les Platgetes \\
\end{tabular} & 2 \\
\hline Playa Norte & 2 & BENICȦSSIM & \\
\hline Playa Sur & 2 & Playa del Voramar & 2 \\
\hline ALCALÀ DE XIVERT & & Playa de la Almadrava & 2 \\
\hline Playa de Les Fonts & 3 & Playa Torre Sant Vicent & 2 \\
\hline Playa del Carregador & 3 & Playa Els Terrers & 2 \\
\hline Playa Romana & 3 & Playa Heliopolis & 2 \\
\hline Playa del Moro & 3 & & \\
\hline
\end{tabular}

Elaboración propia

\subsubsection{Análisis de los factores externos}

La valoración de las playas atendiendo a la accesibilidad desde los centros emisores a los destinos del área de estudio viene condicionada por el análisis de los tres medios de transporte más utilizados en los desplazamientos, es decir por carretera, ferrocarril y aéreo. Pese a que la accesibilidad respecto al transporte por carretera obtiene en el área de estudio la máxima valoración debido a que los desplazamientos desde los principales centros emisores son inferiores a 6 horas, en cambio desciende la puntuación en todas las playas analizadas respecto al ferrocarril, ya que en todos los destinos paran menos del $50 \%$ de los trenes de largo recorrido, incluso en el caso de Alcalà de Xivert-Alcossebre pese a disponer de estación de ferrocarril no para ningún tren de estas características. El descenso de 
valoración también se aprecia en el transporte aéreo ya que el tiempo en acceder desde el aeropuerto de Manises al área de estudio oscila entre 60 y 120 minutos, con lo cual se sitúa en una posición intermedia (Cuadro 4).

Los resultados de las encuestas realizadas en los principales destinos del área de estudio muestran una distribución porcentual donde predominan los visitantes de origen nacional en todos los destinos analizados salvo en Alcossebre, que alcanza el máximo de puntuación dado que el mayor porcentaje corresponde a la demanda de origen internacional (Cuadro 5).

\subsection{La ponderación de los factores y sus variables}

Una vez aplicado el factor de ponderación, la clasificación de las playas atendiendo a las puntuaciones ponderadas, ofrece diferencias entre ellas tanto por lo que respecta a los factores internos como externos

\subsubsection{Factores internos}

\section{A) Características intrínsecas}

Del análisis ponderado de las playas cabe destacar que el litoral de Vinaròs obtiene en su conjunto los resultados menos favorables del área de estudio (Cuadro. 6). De ellas tan sólo las dos urbanas, la del Fortí Fora-Forat y la del Clot, se sitúan en la categoría 3, es decir, un valor medio; a partir de éste, van descendiendo hasta alcanzar la categoría 1 como es el caso de la playa Salinas dada la degradación de su vegetación de saladar, su forma abierta y el predominio de cantos con bloques de escollera. Sobre estos mínimos en las playas de Vinaròs influyen claramente la profundidad de la línea de costa y la tendencia regresiva que experimenta; la falta de análisis sobre la calidad del agua ya que sólo se practica en las dos urbanas y en la del Triador; la escasez de terreno libre, a raíz de la ocupación extensiva del área de influencia; y la ausencia de arena fina.

En Peníscola pese a que ambas playas son de arena su clasificación no sobrepasa la media, aunque destacan por la inexistencia de piedras y su tonalidad; sin embargo son las variables paisajísticas, caso de la forma y del relieve, las que alcanzan los valores mínimos que contrarrestan a los anteriores. Asimismo y de manera particular, la playa Norte presenta una tendencia global regresiva como lo demuestran las constantes regeneraciones a que se ve sometida; en la Sur, es la baja calidad del agua y la escasez de terreno, los factores que inciden también en el descenso de su posicionamiento.

En las playas de Alcalà de Xivert-Alcossebre, vuelven a ser las de arena fina quienes se clasifican con las máximas categorías ya que disponen de granulometrías aceptables con predominio de tonalidades claras; son estables y poco profundas; y la calidad del agua es buena. En cambio pierden valoración respecto al paisaje ya que predominan las superficies de cultivo, además escasea la disponibilidad de terreno, salvo en la del Moro. Por otra parte las playas del litoral sur se escalan entre 2 y 3; aunque disfrutan de mayor naturalidad, como lo atestigua la puntuación del paisaje, siendo la calidad intrínseca la que les confiere esta clasificación dada la ausencia de arena, el retroceso de la costa y la profundidad.

Las playas de la Concha y la de Morro de Gos, de Orpesa, alcanzan la mejor posición del litoral de castellonense obteniendo la clasificación 4, fundamentalmente la primera por su calidad intrínseca aunque en menor medida por el paisaje, donde destaca su forma de bahía. No obstante en ambas, la elevada presión urbanística y la progresiva colmatación del área interna, inciden negativamente en la disponibilidad de terreno para planificar con mayor racionalidad la ordenación turística. 


\section{Cuadro 6}

VALOR PONDERADO DE LAS PLAYAS DEL NORTE DE LA COMUNIDAD VALENCIANA SEGÚN CARACTERÍSTICAS INTRÍNSECAS. FACTORES INTERNOS

\begin{tabular}{|c|c|c|c|c|c|c|c|c|c|c|c|c|c|c|c|}
\hline VARIABLES & 1 & 2 & 3 & 4 & 5 & 6 & 7 & 8 & 9 & 10 & 11 & 12 & 13 & \begin{tabular}{|l|}
$\mathbf{A}$ \\
\end{tabular} & $\mathbf{B}$ \\
\hline $\begin{array}{l}\text { FACTOR DE } \\
\text { PONDERACIÓN }\end{array}$ & 0.04 & 0.10 & 0.04 & 0.04 & 0.10 & 0.10 & 0.10 & 0.04 & 0.10 & 0.04 & 0.04 & 0.10 & 0.16 & & \\
\hline \multicolumn{16}{|l|}{ VINARÓS } \\
\hline $\begin{array}{l}\text { Playa del Triador } \\
\end{array}$ & -0.04 & 0 & -0.04 & -0.04 & -0.30 & 0.20 & 0.20 & 0 & 0.20 & 0 & 0.04 & -0.10 & 0 & 0.12 & 2 \\
\hline Playa de la Barbiguera & -0.04 & 0 & \begin{tabular}{|l|}
-0.04 \\
\end{tabular} & -0.04 & -0.20 & 0 & 0.20 & 0 & 0.20 & 0 & 0.04 & -0.20 & 0 & -0.08 & 2 \\
\hline $\begin{array}{l}\text { Playa del Saldonar } \\
\end{array}$ & -0.04 & 0 & -0.04 & -0.08 & -0.30 & 0 & 0.20 & 0 & 0.10 & 0 & 0.04 & -0.20 & 0 & -0.32 & 2 \\
\hline Playa dels Còssis & -0.04 & 0 & -0.04 & -0.04 & -0.30 & 0 & 0.20 & 0 & 0.20 & 0 & 0 & -0.30 & 0 & -0.32 & 2 \\
\hline Playa Forti- Fora Forat & 0 & 0.20 & -0.04 & -0.08 & -0.20 & 0.20 & 0.20 & 0.08 & 0.10 & 0 & 0 & -0.30 & 0 & 0.16 & 3 \\
\hline Playa del Clot & -0.04 & 0.10 & 0 & 0 & 0 & 0.20 & 0.20 & 0.04 & 0.10 & 0 & 0 & -0.30 & 0 & 0.30 & 3 \\
\hline $\begin{array}{l}\text { Playa Salinas } \\
\end{array}$ & -0.04 & 0 & \begin{tabular}{|l|}
-0.08 \\
\end{tabular} & -0.04 & -0.20 & 0 & 0.20 & 0 & 0 & 0 & 0 & -0.30 & 0 & -0.46 & 1 \\
\hline \multicolumn{16}{|l|}{\begin{tabular}{|l|} 
PENISCOLA \\
\end{tabular}} \\
\hline Playa Norte & 0 & 0 & 0 & -0.04 & -0.30 & 0.20 & 0.20 & 0.12 & 0.10 & 0 & 0.04 & -0.10 & 0 & 0.22 & 3 \\
\hline $\begin{array}{l}\text { Playa Sur } \\
\end{array}$ & -0.04 & 0.10 & 0 & 0.08 & -0.30 & 0 & 0.20 & 0.12 & 0.10 & 0 & 0.04 & -0.20 & 0 & 0.10 & 2 \\
\hline \multicolumn{16}{|l|}{ ALCALȦ DE XIVERT } \\
\hline Playa de Les Fonts & -0.04 & 0.10 & 0 & 0.08 & 0 & 0.10 & 0.20 & 0.12 & 0.10 & 0 & 0.08 & -0.30 & 0 & 0.44 & 3 \\
\hline $\begin{array}{l}\text { Playa del Carregador } \\
\end{array}$ & 0 & 0.20 & 0 & 0 & 0 & 0.20 & 0.20 & 0.12 & 0.20 & 0 & 0.04 & -0.20 & 0 & 0.76 & 4 \\
\hline Playa Romana & 0 & 0.20 & 0 & 0 & 0 & 0.20 & 0.20 & 0.12 & 0.20 & 0 & 0.04 & -0.20 & 0 & 0.76 & 4 \\
\hline Playa del Moro & -0.04 & 0.20 & -0.04 & 0 & 0 & 0.20 & 0.20 & 0.12 & 0.10 & 0 & 0.04 & -0.10 & 0 & 0.68 & 4 \\
\hline $\begin{array}{l}\text { Playa Tres Playas } \\
\end{array}$ & -0.04 & 0.20 & -0.08 & 0 & -0.10 & 0 & 0.20 & 0.12 & 0.20 & 0 & 0.04 & -0.20 & 0 & 0.34 & 3 \\
\hline $\begin{array}{l}\text { Playa Manyetes } \\
\end{array}$ & -0.04 & 0.20 & 0 & -0.04 & 0 & 0.20 & 0.20 & 0.12 & 0.10 & 0 & 0.04 & -0.20 & 0 & 0.58 & 3 \\
\hline $\begin{array}{l}\text { Playa del Serradal } \\
\end{array}$ & -0.04 & 0 & -0.08 & 0 & -010 & 0 & 020 & 0 & 0 & 0.08 & 0.04 & -0.10 & 0 & 0 & 2 \\
\hline Playa Cap i Corp & -0.04 & 0 & -0.04 & -0.04 & -0.10 & 0 & 020 & 0 & 0 & 0.08 & 0.04 & -0.10 & 0 & 0 & 2 \\
\hline \multicolumn{16}{|l|}{\begin{tabular}{|l|} 
ORPESA \\
\end{tabular}} \\
\hline Playa de les Amplàries & -0.04 & 0.10 & -0.04 & 0 & 0 & 0.20 & 0.20 & 0.12 & 0 & 0.08 & 0.04 & 0 & 0 & 0.64 & 3 \\
\hline Playa Morro de Gos & -0.04 & 0.10 & -0.04 & 0.04 & 0 & 0.20 & 0.20 & 0.12 & 0.10 & 0 & 0.08 & -0.10 & 0 & 0.66 & 4 \\
\hline Playa de la Conxa & 0 & 0.10 & 0 & 0 & 0 & 0.20 & 0.20 & 0.12 & 0.20 & 0.12 & 0.04 & -0.20 & 0 & 0.78 & 4 \\
\hline Playa de les Platgetes & -0.04 & 0.30 & -0.04 & 0.04 & 0 & 0 & 0.20 & 0.08 & 0.10 & 0 & 0.08 & -0.30 & 0 & 0.42 & 3 \\
\hline \multicolumn{16}{|l|}{ BENICÁSSIM } \\
\hline $\begin{array}{l}\text { Playa del Voramar } \\
\end{array}$ & -0.04 & 0.20 & 0 & 0 & 0 & 0.20 & 0.20 & 0.12 & 0.10 & 0 & 0.08 & -0.30 & 0 & 0.56 & 3 \\
\hline Playa de la Almadrava & 0 & 0.20 & 0 & 0 & 0 & 0.20 & 0.20 & 0.12 & 0.10 & 0 & 0.08 & -0.30 & 0 & 0.60 & 3 \\
\hline Playa Torre Sant Vicent & 0 & 0.20 & 0 & -0.04 & 0 & 0.20 & 0.20 & 0.12 & 0.10 & 0 & 0 & -0.30 & 0 & 0.48 & 3 \\
\hline $\begin{array}{l}\text { Playa Els Terrers } \\
\end{array}$ & -0.08 & 0.20 & -0.08 & -0.04 & $\begin{array}{ll}-0.30 \\
\end{array}$ & 0.20 & 0.20 & 0.12 & 0 & 0 & 0 & -0.20 & 0 & -0.18 & 2 \\
\hline Playa Heliopolis & 0 & 0 & -0.04 & -0.04 & 0 & 0.20 & 0.20 & 0.12 & 0.10 & 0 & 0.04 & -0.20 & 0 & 0.78 & 4 \\
\hline \multicolumn{16}{|l|}{ VARIABLES: } \\
\hline 2. Granulometría de la arena & 6. Cali & ad del ag & & & & elieve & & & & Puntua & & & & & \\
\hline 3. Presencia de piedras & 7. Ten & eratura d & I agua & & & egetación & & & & Clasifica & & & & & \\
\hline 4. Estabilidad & 8. $\mathrm{Col}$ & de la are & & & 12. I & isponibil & lad de ter & & & & & & & & \\
\hline
\end{tabular}

En Benicàssim a excepción de la playa de Els Terrers que solamente se sitúa en la categoría 2, el resto de las playas alcanzan la media de 3, que incluso se ve superada en la playa de Heliópolis. Ésta ve reforzado su valor ponderado por la anchura de la playa seca y la disponibilidad de terreno en el Quadro de Santiago. Sin embargo ambos valores se ven contrarrestados por la artificialización del paisaje, a causa, al igual que sucede en el resto de playas de litoral benicense, de los peines de espigones al objeto de estabilizar el frente costero.

b) Grado de planificación y ordenación integrada

La categorización del valor ponderado de las playas de Vinaròs y Alcossebre presenta las mayores debilidades del área de estudio en cuanto al grado de planificación y ordenación integrada del recurso (Cuadro 7). De este modo en el caso de Vinaròs sólo logra mantener una posición medio alta la playa del Fortí- Fora Forat, por los valores ponderados altos que consigue en cuanto a las infraestructuras urbanas y a la oferta turística y servicios. En cambio en el resto de playas incide negativamente la escasa oferta tanto de equipamientos como de recursos turísticos complementarios. Asimismo en el litoral de Alcossebre solamente sobresalen las playas de Les Fonts y del Carregador que logran situarse en la categoría 3 debido a que se hallan reforzadas por la oferta turística y los servicios, a excepción de los recursos turísticos complementarios. No obstante el resto de playas logran un valor ponderado mínimo respecto a las infraestructuras básicas y la oferta turística a pesar de disponer la mayoría de ellas de equipamiento recreativo y deportivo. 


\section{Cuadro 7}

VALOR PONDERADO DE LAS PLAYAS DEL NORTE DE LA COMUNIDAD VALENCIANA SEGÚN EL GRADO DE PLANIFICACIÓN Y ORDENACIÓN INTEGRADA.

\section{FACTORES INTERNOS}

\begin{tabular}{|c|c|c|c|c|c|c|c|c|c|c|c|c|c|c|c|c|}
\hline \multirow{3}{*}{\multicolumn{2}{|c|}{ VARIABLES }} & \multicolumn{6}{|c|}{ Infraestructura general y grado de planificación } & \multicolumn{7}{|c|}{ Oferta turística y servicios } & \multirow{4}{*}{$\mathbf{A}$} & \multirow{4}{*}{ B } \\
\hline & & \multicolumn{3}{|c|}{1} & \multirow[t]{2}{*}{2} & \multirow{2}{*}{\multicolumn{2}{|c|}{$3 \quad 4$}} & \multicolumn{5}{|c|}{5} & \multirow{2}{*}{\multicolumn{2}{|c|}{7}} & & \\
\hline & & \multirow{2}{*}{$\begin{array}{ll}1.1 \\
0.15 \\
\end{array}$} & \multirow{2}{*}{$\begin{array}{l}1.2 \\
0.10\end{array}$} & \multirow{2}{*}{\begin{tabular}{|l|l}
1.3 \\
0.05 \\
\end{tabular}} & & & & \multirow{2}{*}{$\begin{array}{l}5.1 \\
0.05 \\
\end{array}$} & \multirow{2}{*}{$\begin{array}{l}5.2 \\
0.05\end{array}$} & \multirow{2}{*}{\begin{tabular}{|l|}
5.3 \\
0.05 \\
\end{tabular}} & \multirow{2}{*}{\begin{tabular}{|l|}
5.4 \\
0.05 \\
\end{tabular}} & \multirow{2}{*}{\begin{tabular}{|l|}
5.5 \\
0.05 \\
\end{tabular}} & & & & \\
\hline & \begin{tabular}{|l|} 
FACTOR DE \\
PONDERACIÓN
\end{tabular} & & & & 0.10 & 0.05 & 0.05 & & & & & & 0.15 & 0.10 & & \\
\hline & \begin{tabular}{|l|l|} 
VINARÓS \\
\end{tabular} & & & & & & & & & & & & & & & \\
\hline & \begin{tabular}{|l|} 
Playa del Triador \\
\end{tabular} & 0.15 & 0.20 & 0 & -0.10 & 0.10 & -0.05 & 0.05 & 0 & 0 & 0 & 0 & 0.30 & 0.10 & 0.75 & 2 \\
\hline & \begin{tabular}{|l} 
Playa de la Barbiguera \\
\end{tabular} & 0.30 & 0.20 & 0 & -0.20 & 0.10 & -0.10 & 0.05 & 0 & 0 & 0 & 0 & 0.15 & 0.10 & 0.60 & 2 \\
\hline & \begin{tabular}{|l|} 
Playa del Saldonar \\
\end{tabular} & 0.30 & 0.10 & 0 & -0.20 & 0.10 & -0.10 & 0.05 & 0 & 0 & 0 & 0 & 0.15 & 0.10 & 0.50 & 2 \\
\hline & \begin{tabular}{|l|} 
Playa dels Còssis \\
\end{tabular} & 0.30 & 0.10 & 0.10 & -0.20 & 0.10 & -0.15 & 0.10 & 0 & 0 & 0 & 0 & 0.15 & 0.10 & 0.60 & 2 \\
\hline & \begin{tabular}{|l|} 
Playa Forti- Fora Forat \\
\end{tabular} & 0.30 & 0.30 & 0.10 & -0.30 & -0.10 & \begin{tabular}{|l|}
-0.15 \\
\end{tabular} & 0.05 & \begin{tabular}{|l|l|}
0 \\
\end{tabular} & 0.15 & 0.15 & 0.15 & 0.45 & 0.30 & 1.40 & 3 \\
\hline & \begin{tabular}{|l|} 
Playa del Clot \\
\end{tabular} & 0.30 & 0.10 & 0 & -0.20 & -0.15 & -0.15 & 0.05 & 0 & 0 & 0.10 & 0.05 & 0.30 & \begin{tabular}{|l|l|}
0.10 \\
\end{tabular} & 0.50 & 2 \\
\hline & \begin{tabular}{|l|} 
Playa Salinas \\
\end{tabular} & 0.30 & 0 & 0 & -0.20 & 0.15 & -0.10 & 0.05 & 0 & 0 & 0 & 0 & 0.15 & \begin{tabular}{|l|}
0.10 \\
\end{tabular} & 0.45 & 1 \\
\hline & \begin{tabular}{|l|} 
PENISCOLAA \\
\end{tabular} & & & & & & & & & & & & & & & \\
\hline & \begin{tabular}{|l|} 
Playa Norte \\
\end{tabular} & 0.45 & 0.30 & 0.10 & -0.30 & 0.10 & 0 & 0.15 & 0.05 & 0.05 & 0.15 & 0.15 & 0.45 & 0.30 & 1.95 & 4 \\
\hline & \begin{tabular}{|l} 
Playa Sur \\
\end{tabular} & 0.45 & 0.30 & 0.10 & -0.20 & 0 & 0 & 0.05 & 0 & 0.15 & 0.10 & 0.15 & 0.45 & 0.20 & 1.75 & 4 \\
\hline & \begin{tabular}{|l} 
ALCALA் DE XIVERT \\
\end{tabular} & & & & & & & & & & & & & & & \\
\hline & \begin{tabular}{|l} 
Playa de Les Fonts \\
\end{tabular} & 0.30 & 0.30 & 0.10 & 0 & \begin{tabular}{|l|l|}
0.10 \\
\end{tabular} & \begin{tabular}{|l|}
-0.15 \\
\end{tabular} & 0.05 & 0 & 0.05 & 0.15 & 0 & 0.30 & 0.20 & 1.40 & 3 \\
\hline & \begin{tabular}{|l} 
Playa del Carregador \\
\end{tabular} & 0.30 & 0.10 & 0 & \begin{tabular}{|l|l|}
-0.20 \\
\end{tabular} & 0.10 & \begin{tabular}{|l|}
-0.10 \\
\end{tabular} & 0.05 & 0 & \begin{tabular}{|l|}
0.15 \\
\end{tabular} & 0.10 & 0.05 & 0.45 & 0.20 & 1.30 & 3 \\
\hline & Playa Romana & 0.15 & 0 & 0 & 0 & 0.10 & \begin{tabular}{|l|}
-0.10 \\
\end{tabular} & 0.05 & 0 & 0 & 0.10 & 0 & 0.45 & 0.20 & 0.95 & 2 \\
\hline & \begin{tabular}{|l|} 
Playa del Moro \\
\end{tabular} & 0.15 & 0 & 0 & 0 & 0.10 & -0.15 & 0.10 & 0 & 0 & 0.10 & 0 & 0.30 & 0.10 & 0.70 & 2 \\
\hline & \begin{tabular}{|l} 
Playa Tres Playas \\
\end{tabular} & 0.15 & 0 & 0 & \begin{tabular}{|l|}
-0.10 \\
\end{tabular} & \begin{tabular}{|l|l|}
0.10 \\
\end{tabular} & -0.05 & 0.10 & 0 & 0 & 0 & 0 & 0.15 & \begin{tabular}{|l|l|}
0.10 \\
\end{tabular} & \begin{tabular}{|l|l|}
0.45 \\
\end{tabular} & 1 \\
\hline & \begin{tabular}{|l|} 
Playa Manyetes \\
\end{tabular} & 0.15 & 0 & 0 & \begin{tabular}{|l|}
-0.10 \\
\end{tabular} & \begin{tabular}{|l|l|}
0.10 \\
\end{tabular} & \begin{tabular}{|c|}
-0.05 \\
\end{tabular} & 0.05 & 0 & 0 & 0.10 & 0 & 0.30 & \begin{tabular}{|l|l|}
0.10 \\
\end{tabular} & \begin{tabular}{|l|l|}
0.65 \\
\end{tabular} & 2 \\
\hline & \begin{tabular}{|l} 
Playa del Serradal \\
\end{tabular} & 0.15 & 0 & 0 & \begin{tabular}{|l|}
-0.10 \\
\end{tabular} & 0.10 & \begin{tabular}{|c|}
-0.05 \\
\end{tabular} & 0.05 & 0 & 0 & 0 & 0 & 0.15 & 0.10 & 0.40 & 1 \\
\hline & \begin{tabular}{|l} 
Playa Cap i Corp \\
\end{tabular} & 0.15 & 0 & 0 & -0.10 & \begin{tabular}{|l|l|}
0.10 \\
\end{tabular} & -0.05 & 0 & 0 & 0 & 0 & 0.05 & 0.15 & 0.10 & 0.40 & 1 \\
\hline & \begin{tabular}{|l} 
ORPESA \\
\end{tabular} & & & & & & & & & & & & & & & \\
\hline & \begin{tabular}{|l|} 
Playa de les Amplàries \\
\end{tabular} & 0.15 & 0.10 & 0 & -0.30 & 0.10 & \begin{tabular}{|l|l|}
-0.10 \\
\end{tabular} & 0.15 & \begin{tabular}{|l|l}
0 \\
\end{tabular} & 0 & 0.15 & 0 & 0.15 & 0 & 0.40 & 1 \\
\hline & \begin{tabular}{|l|} 
Playa Morro de Gos \\
\end{tabular} & 0.45 & 0.30 & 0.15 & -0.20 & \begin{tabular}{|l|l|}
0.10 \\
\end{tabular} & -0.15 & 0.05 & 0 & 0 & 0.15 & 0.05 & 0.45 & 0.20 & 1.55 & 4 \\
\hline & \begin{tabular}{|l|} 
Playa de la Conxa \\
\end{tabular} & 0.45 & 0.30 & 0.10 & -0.30 & \begin{tabular}{|l|l|}
0.10 \\
\end{tabular} & -0.15 & 0.05 & 0 & 0.05 & 0.10 & 0.05 & 0.45 & \begin{tabular}{|l|}
0.30 \\
\end{tabular} & 1.50 & 3 \\
\hline & \begin{tabular}{|l|} 
Playa de les Platgetes \\
\end{tabular} & 0.15 & 0.30 & 0.10 & -0.20 & \begin{tabular}{|l|l|}
0.15 \\
\end{tabular} & 0 & 0.10 & 0 & 0 & 0.05 & 0.05 & 0.15 & \begin{tabular}{|l|}
0.10 \\
\end{tabular} & 0.95 & 2 \\
\hline & \begin{tabular}{|l} 
BENICÁSSIM \\
\end{tabular} & & & & & & & & & & & & & & & \\
\hline & \begin{tabular}{|l|} 
Playa del Voramar \\
\end{tabular} & 0.45 & 0.30 & 0.10 & -0.20 & 0 & \begin{tabular}{|c|}
-0.05 \\
\end{tabular} & 0.10 & 0 & 0 & 0.15 & 0.05 & 0.30 & 0.10 & 1.30 & 3 \\
\hline & \begin{tabular}{|l|} 
Playa de la Almadrava \\
\end{tabular} & 0.45 & 0.30 & 0.10 & \begin{tabular}{|l|}
-0.30 \\
\end{tabular} & 0.10 & \begin{tabular}{|l|}
-0.10 \\
\end{tabular} & 0.05 & 0 & 0.05 & 0.10 & 0.05 & 0.45 & 0.10 & 1.35 & 3 \\
\hline & \begin{tabular}{|l} 
Playa Torre Sant Vicent \\
\end{tabular} & 0.45 & 0.30 & 0.05 & -0.30 & \begin{tabular}{|l|l|}
0.10 \\
\end{tabular} & 0 & 0.05 & 0 & 0 & 0.10 & 0.05 & 0.30 & 0.20 & 1.30 & 3 \\
\hline & \begin{tabular}{|l|} 
Playa Els Terrers \\
\end{tabular} & 0.30 & 0.10 & 0.10 & \begin{tabular}{|l|}
-0.30 \\
\end{tabular} & \begin{tabular}{|l|}
0.10 \\
\end{tabular} & \begin{tabular}{|l|}
-0.15 \\
\end{tabular} & 0.15 & 0 & 0.05 & 0.15 & 0 & 0.45 & 0.10 & 1.05 & 3 \\
\hline & \begin{tabular}{|l|} 
Playa Heliopolis \\
\end{tabular} & 0.45 & 0.30 & 0 & -0.30 & 0.10 & 0 & 0.05 & 0 & 0.05 & 0.10 & 0 & 0.45 & 0.20 & 1.40 & 3 \\
\hline $\mathrm{VAI}$ & IABLES: & & & & & & & & & & & & & & & \\
\hline 1 & Infraestructuras básicas & & & Equipa & entos $y$ & ursos & & & & rvicios & & & & & & \\
\hline 1.1 & Infraestructuras urbanas & & & 1. Alojar & ento com & rcial y c & aplement & & & ñalizaci & y servi & de info & ación & & & \\
\hline 1.2 & Características de los accesos & & & 2. Resid & cial turíst & & & & & intuació & & & & & & \\
\hline 1.3 & Aparcamientos & & & 3. Establ & imientos & omercial & & & & lasificac & & & & & & \\
\hline 2 & Características de la urbanización & & & 4. Equip & hiento de & ortivo $\mathrm{y}$ & creativo & & & & & & & & & \\
\hline 3 & Usos del suelo en origen & & & 5 Recurs & turístico & compler & ntarios & & & & & & & & & \\
\hline 4 & Densidad & & & & & & & & & & & & & & & \\
\hline
\end{tabular}

Mejor posicionadas se encuentran las playas de Orpesa y Benicàssim. Así el litoral benicense las cinco playas se sitúan en la categoría 3 donde intervienen la valoración ponderada óptima que consiguen en gran medida las infraestructuras básicas y los servicios. Sin embargo estos óptimos se ven descompensados por la excesiva intensidad de la urbanización, la estacionalidad del destino y el actual escaso valor jerárquico de los recursos turísticos complementarios. Por su parte la valoración ponderada de las playas de Orpesa traduce sensibles diferencias entre ellas, las que se reflejan en la buena clasificación de las playas de la Concha y la de Morro de Gos alcanzando respectivamente las categorías 4 y 3, la cual se ve descompensada por la de Les Amplàries y en menor medida por Les Platgetes. Respecto a la playa de Les Amplàries pese a que la oferta de alojamiento comercial supera al complementario se sitúa en la puntuación mínima del área de estudio, en ello influyen las escasas infraestructuras básicas de que dispone, la apuesta por un modelo de desarrollo urbanístico intensivo en altura, la reducida oferta comercial, la ausencia de señalización y servicio de información.

En esta línea ascendente las playas de Peníscola logran posicionarse en la categoría 4, consiguiendo asimismo las puntuaciones más altas del área de estudio. A excepción de los valores excesivamente negativos respecto a las características de la urbanización y a los mínimos relativos que presentan en cuanto a la oferta de apartamentos regulados, destacan por la máxima ponderación obtenida en las infraestructuras urbanas, los recursos turísticos complementarios y los servicios ofertados. 
Cuadro 8

VALORACIÓN PONDERADA DE LAS PLAYAS DEL NORTE DE LA COMUNIDAD VALENCIANA SEGÚN LA ACCESIBILIDAD. FACTORES EXTERNOS

\begin{tabular}{|l|c|l|c|}
\hline & $\begin{array}{c}\text { ACCESIBILIDAD } \\
\text { INTERNA }\end{array}$ & & $\begin{array}{c}\text { ACCESIBILIDAD } \\
\text { INTERNA }\end{array}$ \\
\cline { 2 - 4 } & $\begin{array}{c}\text { A los puntos de } \\
\text { destino }\end{array}$ & & $\begin{array}{c}\text { A los puntos de } \\
\text { destino }\end{array}$ \\
\hline \multicolumn{1}{|c|}{ PONDERACIÓN } & $\mathbf{0 . 5 0}$ & \multicolumn{1}{|c|}{ PONDERACIÓN } & $\mathbf{0 . 5 0}$ \\
\hline VINARÒS & 1.00 & Playa Tres Playas & 0.50 \\
\hline Playa del Triador & 1.00 & Playa Manyetes & 0.50 \\
\hline Playa de la Barbiguera & 1.00 & Playa del Serradal & 0.50 \\
\hline Playa del Saldonar & 1.00 & ORPESA & 1.00 \\
\hline Playa dels Còssis & 1.00 & Playa de les Amplàries & 1.00 \\
\hline Playa Forti - Fora Forat & 1.00 & Playa Morro de Gos & 1.00 \\
\hline Playa del Clot & 1.00 & Playa de la Conxa & 1.00 \\
\hline Playa Salinas & & Playa de les Platgetes & \\
\hline PENÍSCOLA & 1.00 & BENICÀSSIM & 1.00 \\
\hline Playa Norte & 1.00 & Playa del Voramar & 1.00 \\
\hline Playa Sur & & Playa de la Almadrava & 1.00 \\
\hline ALCALÀ DE XIVERT & 0.50 & Playa Torre Sant Vicent & 1.00 \\
\hline Playa de Les Fonts & 0.50 & Playa Els Terrers & 1.00 \\
\hline Playa del Carregador & 0.50 & Playa Heliopolis & \\
\hline Playa Romana & 0.50 & & \\
\hline Playa del Moro & & & \\
\hline Elay & & \\
\hline
\end{tabular}

Elaboración propia

VALORACIÓN PONDERADA DE LAS PLAYAS DEL NORTE DE LA COMUNIDAD

VALENCIANA SEGÚN EL PREDOMINIO DE DEMANDA QUE GENERAN. FACTORES EXTERNOS

\begin{tabular}{|l|c|l|c|}
\hline & DEMANDA & & DEMANDA \\
\cline { 2 - 3 } & $\begin{array}{c}\text { Origen de la } \\
\text { demanda }\end{array}$ & & $\begin{array}{c}\text { Origen de la } \\
\text { demanda }\end{array}$ \\
\hline PONDERACIÓN & $\mathbf{0 . 5 0}$ & PONDERACIÓN & $\mathbf{0 . 5 0}$ \\
\hline VINARÒS & & Playa Tres Playas & 1.50 \\
\hline Playa del Triador & 1.00 & Playa Manyetes & 1.50 \\
\hline Playa de la Barbiguera & 1.00 & Playa del Serradal & 1.50 \\
\hline Playa del Saldonar & 1.00 & Playa Cap i Corp & 1.50 \\
\hline Playa dels Còssis & 1.00 & ORPESA & 1.00 \\
\hline Playa Forti - Fora Forat & 1.00 & Playa de les Amplàries & 1.00 \\
\hline Playa del Clot & 1.00 & Playa Morro de Gos & 1.00 \\
\hline Playa Salinas & 1.00 & Playa de la Conxa & 1.00 \\
\hline PENíSCOLA & & Playa de les Platgetes & \\
\hline Playa Norte & 1.00 & BENICÀSSIM & 1.00 \\
\hline Playa Sur & 1.00 & Playa del Voramar & 1.00 \\
\hline ALCALÀ DE XIVERT & & Playa de la Almadrava & 1.00 \\
\hline Playa de Les Fonts & 1.50 & Playa Torre Sant Vicent & 1.00 \\
\hline Playa del Carregador & 1.50 & Playa Els Terrers & 1.00 \\
\hline Playa Romana & 1.50 & Playa Heliopolis & \\
\hline Playa del Moro & 1.50 & & \\
\hline
\end{tabular}

Elaboración propia 


\subsubsection{Factores externos}

Valoración ponderada de la accesibilidad y de la demanda

De la valoración ponderada de la accesibilidad desde los principales puntos de destino al área de estudio, los resultados obtenidos muestran una situación bastante ventajosa respecto al transporte por carretera ya que el tiempo empleado en los desplazamientos no suele sobrepasar las seis horas. Sin embargo el principal déficit de accesibilidad reside en el transporte por ferrocarril, debido por una parte a que los trenes de velocidad alta no efectúan ninguna parada y a la práctica inoperatividad de la estación de Alcalà de XivertAlcossebre en la que además tampoco realizan paradas los trenes de largo recorrido. Este déficit es menor en lo que atañe al transporte aéreo ya que el desplazamiento desde el aeropuerto de Manises al área de estudio no supera las dos horas. Con lo que antecede la valoración ponderada de los tres medios de transporte considerados es evidente que no logra alcanzar la puntuación máxima pero, excepto Alcossebre que se sitúa en el valor mínimo, el resto de destinos consiguen sobrepasar la media aún considerando los déficits aludidos (Cuadro 8).

La valoración de los factores externos se completa con el análisis ponderado de los resultados obtenidos respecto al predominio de demanda que generan las playas del área de estudio. Como se puede apreciar en el cuadro 9, la ponderación de la variable indica una posición medio alta en la mayor parte de los destinos, la cual se corresponde con la demanda de origen nacional. Esta posición se ve superada por Alcossebre que alcanza el máximo valor ponderado por el predominio de la demanda de origen internacional.

\section{Conclusiones}

El carácter integrado de la metodología de análisis y evaluación del recurso básico de las playas, conduce a implementar la evaluación conjunta de las valoraciones de los factores internos y externos del recurso. De este modo el Cuadro 10 refleja, a partir de los resultados de las puntuaciones de cada bloque de variables, la clasificación final de las playas. La puntuación final indica que la playa Norte de Peníscola y la playa de la Concha de Orpesa son las mejor valoradas, situándose en el extremo opuesto la playa Salinas y la del Saldonar, ambas en Vinaròs.

Atendiendo a la clasificación final todo indica que existe una correlación entre playas de arena fina y categorías medio altas a excepción de la playa del Clot de Vinaròs y la playa Tres Playas d'Alcossebre; este dato confirma el elevado grado de atracción turística que posee el recurso. Además teniendo en cuenta el máximo y mínimo teórico que pueden alcanzar, 63 y -27 respectivamente, cabe destacar que ninguna de las playas analizadas obtiene valores negativos; asimismo respecto a las mejor posicionadas, es decir aquellas que alcanzan la categoría 3, se corresponden con los municipios de mayor dinamismo.

Sin embargo frente a este dinamismo es cierto que las puntuaciones obtenidas no son excesivamente altas, lo cual denota una serie de debilidades que se acusan más en los factores internos del recurso. Es precisamente en el grado de planificación y ordenación, y en algunas variables que conforman las características intrínsecas donde es posible generar acciones de mejora de la calidad que conlleven a la dinamización y diferenciación del destino reforzando el producto y especialmente el recurso básico que lo sustenta. En este sentido es necesario apostar por una utilización más racional del territorio con desarrollos urbanísticos mejor integrados en el paisaje y que no se traduzcan en la mera producción de suelo para el mercado inmobiliario; en ello juega la experiencia adquirida, las exigencias 
Cuadro 9

\section{EVALUACIÓN GLOBAL DE LAS PLAYAS DEL NORTE DE LA COMUNIDAD VALENCIANA}

\begin{tabular}{|c|c|c|c|c|c|c|}
\hline Factores & A & $\mathrm{B}$ & $\mathrm{C}$ & $\mathrm{D}$ & Puntuación & Clasificación \\
\hline \multicolumn{7}{|l|}{ VINARÒS } \\
\hline Playa del Triador & 0 & 7 & 2 & 2 & 11 & 2 \\
\hline Playa de la Barbiguera & -2 & 5 & 2 & 2 & 7 & 2 \\
\hline Playa del Saldonar & -5 & 4 & 2 & 2 & 3 & 2 \\
\hline Playa dels Còssis & -5 & 6 & 2 & 2 & 5 & 2 \\
\hline Playa Forti- Fora Forat & 1 & 15 & 2 & 2 & 20 & 3 \\
\hline Playa del Clot & 3 & 2 & 2 & 2 & 9 & 2 \\
\hline Playa Salinas & -7 & 4 & 2 & 2 & 1 & 2 \\
\hline \multicolumn{7}{|l|}{ PENÍSCOLA } \\
\hline Playa Norte & 4 & 24 & 2 & 2 & 32 & 4 \\
\hline Playa Sur & 4 & 20 & 2 & 2 & 28 & 3 \\
\hline \multicolumn{7}{|l|}{ ALCALÀ DE XIVERT } \\
\hline Playa de Les Fonts & 8 & 15 & 1 & 3 & 27 & 3 \\
\hline Playa del Carregador & 10 & 14 & 1 & 3 & 28 & 3 \\
\hline Playa Romana & 10 & 9 & 1 & 3 & 23 & 3 \\
\hline Playa del Moro & 8 & 7 & 1 & 3 & 19 & 3 \\
\hline Playa Tres Playas & 4 & 5 & 1 & 3 & 13 & 2 \\
\hline Playa Manyetes & 7 & 7 & 1 & 3 & 18 & 3 \\
\hline Playa del Serradal & 0 & 4 & 1 & 3 & 8 & 2 \\
\hline Playa Cap i Corp & 0 & 4 & 1 & 3 & 8 & 2 \\
\hline \multicolumn{7}{|l|}{ ORPESA } \\
\hline Playa de les Amplàries & 9 & 6 & 2 & 2 & 19 & 3 \\
\hline Playa Morro de Gos & 9 & 15 & 2 & 2 & 28 & 3 \\
\hline Playa de la Conxa & 12 & 15 & 2 & 2 & 31 & 3 \\
\hline Playa de les Platgetes & 6 & 13 & 2 & 2 & 23 & 3 \\
\hline \multicolumn{7}{|l|}{ BENICÀSSIM } \\
\hline Playa del Voramar & 8 & 14 & 2 & 2 & 26 & 3 \\
\hline Playa de la Almadrava & 9 & 14 & 2 & 2 & 27 & 3 \\
\hline Playa Torre Sant Vicent & 6 & 14 & 2 & 2 & 24 & 3 \\
\hline Playa Els Terrers & -1 & 12 & 2 & 2 & 15 & 2 \\
\hline Playa Heliopolis & 5 & 14 & 2 & 2 & 23 & 3 \\
\hline
\end{tabular}
A: Características intrínsecas
B: Grado de planificación y ordenación integrada
C: Accesibilidad interna
D: Demanda

Elaboración propia

de la demanda y la escasez de suelo que aún se mantiene sin ocupar en el frente costero. De la misma manera la espectacular expansión territorial del desarrollo turístico-residencial trae consigo una significativa oferta no regulada de apartamentos turísticos, lo cual no incide en la recualificación del destino. Además este monocultivo origina deficiencias tanto en la regulación como en la densidad de los aparcamientos. En cuanto a la oferta turística si bien el equipamiento recreativo y deportivo aparece bastante bien posicionado, en cambio el área de estudio presenta déficits en alojamiento comercial, así como en la 
activación de los recursos turísticos complementarios ubicados en el área interna del recurso básico. Respecto a las características intrínsecas se necesita solucionar los problemas de calidad de agua, especialmente en la playa Sur de Peníscola y en la de Les Fonts de Alcossebre, y aumentar la densidad de la red de muestreo; evitar en lo posible la artificialización del frente costero por su impacto negativo en el paisaje; y preservar los ecosistemas litorales dada su elevada singularidad y fragilidad.

\section{Bibliografía}

AVT. (2001): El turismo en la Comunidad Valenciana. Generalitat Valenciana. Agència Valenciana del Turisme. Valencia.

BARRAGÁN, J.M. (1997): Medio ambiente y desarrollo en áreas litorales. Oikos-tau. Barcelona.

BLÀZQUEZ i SALOM, M. (1994): «La platja d'es Trenc, un exemple d'espai natural protegit sotmés a forta pressió recreativa informal, amb superació dels llindars de capacitat de càrrega ecológica i recreativa«, en Desenvolupament turístic a la Mediterrània durant el segle XX. Institut d'Estudis Baleàrics. Palma, pp. 117-126.

BOTE GÓMEZ, V. (1990): Planificación económica del turismo: de una estrategia masiva a una estrategia artesanal. Trillas. México D.F. 373 pp.

CHAVERRI, R. (1989): «Coastal management the Costa Rica experience», en $5^{\text {th }}$ Symposium on Coastal and Ocean Management. American Society of Civil Engineering, pp. 1112-1124.

CHRISTOFOLETTI, A. y PIRES NETO, A.G. (1990): «Estudio comparativo de las variables de la morfometría planimétrica de las playas del litoral paulista (Brasil)», en Revista de Geografía, Vol. XIV. Universitat de Barcelona. Departament de Geografía. Barcelona. pp. 27-38.

GUNN, L.A. (1988): Tourism planning. Taylor \& Francis. New York. 357 pp.

LEATHERMAN, S.P. (1997): «Beach Ratio System», en Journal of coastal research, no 13 (1). pp 254-256.

LÓPEZ OLIVARES, D. (1990): Espacio turístico residencial en las tierras castellonenses. Sociedad Castellonense de Cultura. Estudios Económicos, XI. Gráficas Montañés. Castellón. 249 pp.

LÓPEZ OLIVARES, D. (1998): La ordenación y planificación turística integrada de los recursos territoriales turísticos. Publicacions de la Universitat Jaume I. Castellón. 301 pp.

LÓPEZ OLIVARES, D. (1998): «Características del desarrollo turístico castellonense y el proceso metodológico en la planificación de los espacios turísticos», en Revista Valenciana d'Estudis Autonòmics, $\mathrm{n}^{\mathrm{o}} 22 \mathrm{La}$ hora del euro. Estudios Territoriales. Generalitat Valenciana. Conselleria de Presidència. pp. 103-128.

MORGAN, R. (1999): «A novel user-based rating system for tourist beaches», en Tourist Management, no 20, pp. 393-410.

NAVALÓN GARCÍA, Mª R. (2001): Agricultura y turismo en la franja costera de la Comunidad Valenciana. Comité Económico y Social de la Comunidad Valenciana. CES. no 10, Economía y Empresa. Valencia. 599 pp.

PEARCE, D. (1988): Desarrollo turístico. Su planificación y ubicación geográficas. Trillas. México. D.F. 169 pp.

QUEREDA SALA, J. y LÓPEZ OLIVARES, D. (1986-1987): «Oscilaciones del nivel marino en Castellón», en Millars, XI. Colegio Universitario de Castellón, pp. 7-16.

TORRES ALFONSEA, F.J. (1997): Ordenación del litoral de la Costa Blanca. Publicaciones de la Universidad de Alicante, $269 \mathrm{pp}$.

VERA REBOLLO, F. et al. (2001): Planificación y gestión del desarrollo turístico sostenible: propuestas para la creación de un sistema de indicadores. Documentos de Trabajo 1. Instituto Universitario de Geografía. Universidad de Alicante, $71 \mathrm{pp}$.

WILLIAMS, A.T.; LEATHERMAN, S.P.; SIMMONS, S.L. (1993): «Beach Aesthetic Values», en Interdisciplinary Discussions of Coastal Research and Coastal Management. Francfurt.

WILLIAMS, A.T.; MORGAN, R. (1995): «Beach Award and Rating Systems», en Shore and Beach, $\mathrm{n}^{\mathrm{o}}$ 63(4), pp. 29-33. 
